Portland State University

PDXScholar

\title{
The Urban Oak Savanna: Evaluating Co-Design and Collaborative Land Management in Downtown Portland, Oregon
}

Haley Jane Dunham

Portland State University

Follow this and additional works at: https://pdxscholar.library.pdx.edu/honorstheses

Let us know how access to this document benefits you.

\section{Recommended Citation}

Dunham, Haley Jane, "The Urban Oak Savanna: Evaluating Co-Design and Collaborative Land Management in Downtown Portland, Oregon" (2018). University Honors Theses. Paper 601. https://doi.org/10.15760/honors.611

This Thesis is brought to you for free and open access. It has been accepted for inclusion in University Honors Theses by an authorized administrator of PDXScholar. Please contact us if we can make this document more accessible: pdxscholar@pdx.edu. 
The Urban Oak Savanna: Evaluating Co-Design and Collaborative Land Management in Downtown Portland, Oregon

\author{
by \\ Haley Jane Dunham
}

An undergraduate honors thesis submitted in partial fulfillment of the requirements for the degree of
Bachelor of Arts
in
University Honors
and

Anthropology

Thesis Adviser

Dr. Jeremy Spoon

Portland State University 


\section{Table of Contents}

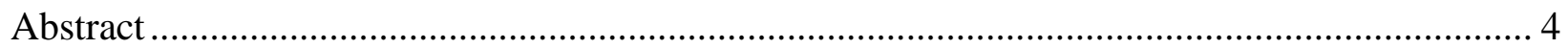

Introduction: The Anthropology of Design and Urban Green Spaces ..................................... 5

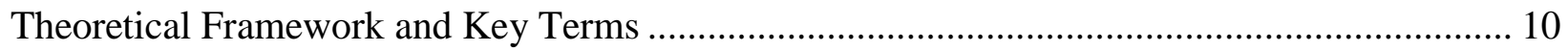

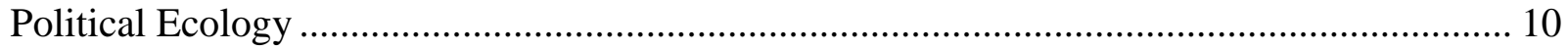

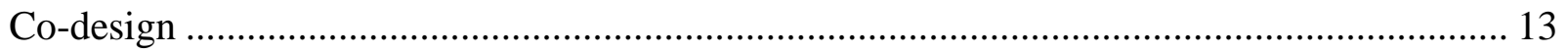

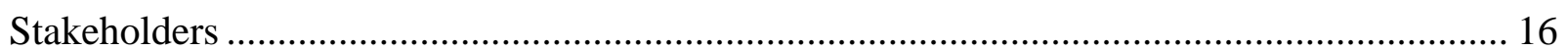

Context: The Urban Oak Savanna .................................................................................. 17

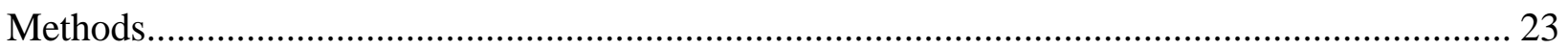

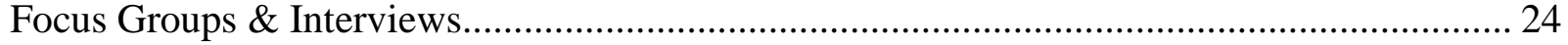

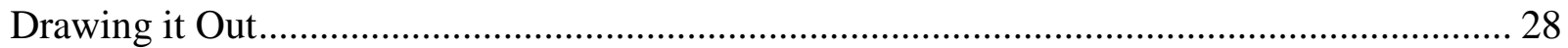

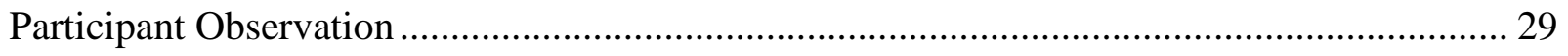

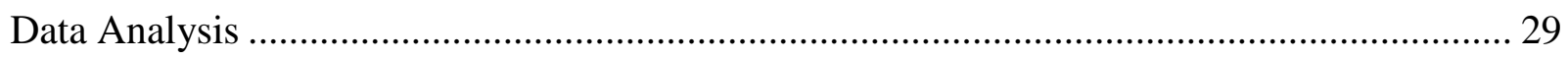

Epistemic Starting Points: Reflexivity \& Positioning ..................................................... 30

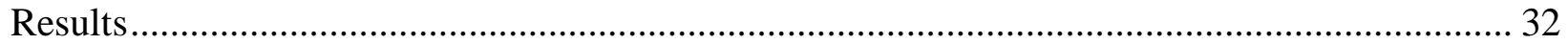

Raising the Stakes: A Narrative Portrait of Savanna Relationships...................................... 32

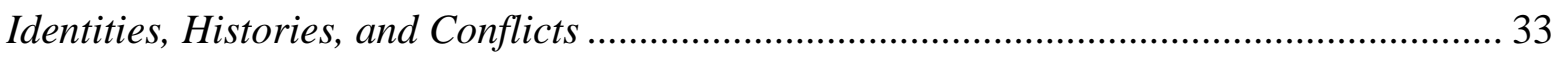

Competing Models, Converging Systems ................................................................... 41

The Shared Imagination: Deconstructing Collaborative Urban Design............................... 46

Evaluating Motivating Factors and Methods ............................................................. 47

Active and Passive Uses: Imagining the Imagination ...................................................... 54

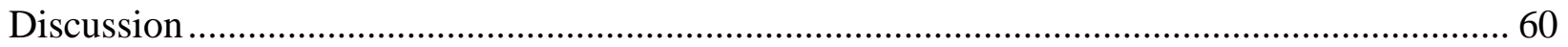

Conclusion: Towards an Ethnographically Informed Design Praxis..................................... 64

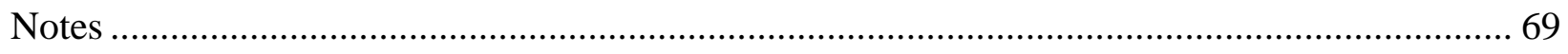

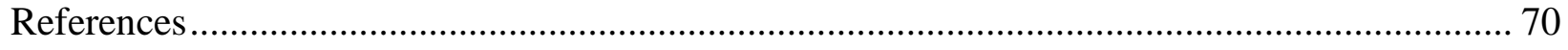

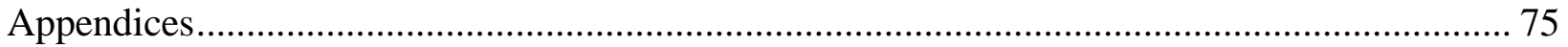

Appendix A: Data Collection Instruments (Interviews and Focus groups) .......................... 75

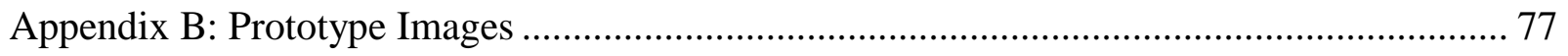

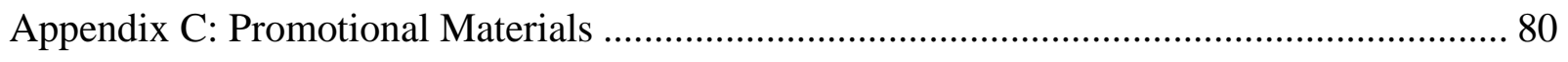

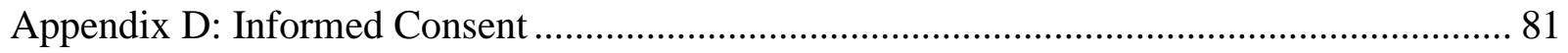




\section{Acknowledgments}

This research would not have been possible without the Oak Savanna, thank you for all the moments we've shared. And to my dog, Bofu, thank you for always taking me to unfamiliar places. I dedicate this thesis to every person who helps fight for the livelihood and longevity of the Oak Savanna. You inspire me.

An additional thanks to all of the wonderful professors and mentors who have helped guide me through this work and supported me with love and empathy, including my amazing advisor, Dr. Jeremy Spoon. 


\section{Abstract}

In downtown Portland, Oregon, Portland State University (PSU) has composed a small Oak Savanna ecosystem, no bigger than the average classroom, nuzzled into the contours of the built environment. Many different stakeholders habitually use this urban green space, some of whom may consider their interests oppositional. These groups include PSU's Indigenous Nations Studies community and the local dog owning community, who have historically had difficulties sharing the space for different uses. Because there are so many diverse interests in the space, planners from PSU facilitated co-design meetings, or "charettes", in which stakeholders collaboratively imagined what the space could be with the help of a contracted landscape design firm. This study used the co-creative approach to the Oak Savanna on the campus of Portland State University as a case study for evaluating the process of co-design in the urban environment, especially as it applies to ecological restoration projects. I ask whether various stakeholder's interests are equally represented at the Oak Savanna and whether the co-design process took into account, and further, represented the ideas and needs of those who use and love the Oak Savanna. Using a mixed-methods approach with one focus group, three in-depth interviews, and participant observation as my primary methods and artistic exercises and archival research as my secondary methods, I assessed stakeholder's interests both independently, in the context of the co-design process, and in the context of the finished, co-designed prototype. I argue that the codesign process is useful for uncovering the socio-material relationships between stakeholder groups and place, by examining the role of expertise in assigning identity through design. This study examines the role of expertise and competing epistemologies in the co-design process and its relevance to ethnographic concern, which has been largely unexplored by anthropological inquiry. 


\section{Introduction: The Anthropology of Design and Urban Green Spaces}

Anthropologists have long recognized the bidirectional influence of the built environment on our societies and vice versa. Famous anthropologists such as Henry Lewis Morgan (1881), Amos Rapoport (1969), and Pierre Bourdieu (1990) have been pontificating about how culture penetrates even the minutiae of architectural design, exploring social life's influence on built form. Anthropologists are, of course, famous for recognizing the interpretive potential of any object or item that results from the human mind, body, or collective, historically being the territory of the (sub)discipline of archaeology. But as a multi-faceted scholarship that is also famous for critical evaluations of knowledge and expertise, socio-cultural anthropologists also explore the power of design, being not just the re-invention of form, but also action and affect all at once (Murphy 2016: 440). This has led to more critical examinations of the architect, designer, and engineer as social figures. Anthropologists have been useful for elucidating the hidden features of design that go unnoticed without careful attention from the critical eye by examining design's connections to broader social themes, such as economic development (Milestone 2007) or technology and futurism (Hunt 2010). Anthropologists do not merely criticize the hidden axioms of design, they have also made pragmatic contributions to design practice, unweaving complex arrangements of designer, designed thing, and stakeholder relationships (Larsen \& Have 2012, Squires \& Byrne 2002, Graffam 2010, Gunn \& Donovan 2012: 1, Harvey \& Knox 2015, Murphy 2016: 440). Although the discipline of anthropology has had its eyes fixed on the process of giving form for quite some time, it is only recently that anthropologists have turned their gaze to designers themselves (Murphy 2016: 435), hoping to understand the expert behind the artifact. 
The influence is bidirectional. Designers have also taken an interest in anthropologists and made considerable contributions to a new discipline, widening the anthropological tool kit to include new and exciting ethnographic methods for collaboration (Gatt \& Ingold 2013).

Designers also dominate professions concerned with the cultural climate and undertake projects that necessitate working with people and public opinion, much like anthropology. However, our methodological approaches differ in their research protocols, intent, and styles of engagement (Hunt 2010). Thus, anthropologists and designers have begun to be in conversation with one another more directly about how far this influence should extend. Some anthropologists are resisting the adoption of design practices, arguing that design has yet to undergo a reflexive understanding of itself, highlighting the different approaches between the two disciplines. Design anthropologist Lucy Suchman (2011) comments on how design's historical deficiency of selfcriticism has caused designers to ignore "that a responsible practice is one characterized by humility rather than hubris, aspiring not to massive change or discontinuous innovation but to modest interventions within ongoing, continually shifting...landscapes" (pg. 16).

But the discipline of design, with its infinite scales and applications, is undeterred. In recent years more than ever before, designers have taken particular interest in the concept of codesign, or designing directly with the public. In these new and exciting arenas of innovation, designers have worked with different internal and external stakeholder groups to co-create everything from services (Pirinen 2016) to entire cities (Hassen et. al. 2007). Within the realm of urban planning, scholars have taken a particular interest in how urban spaces can be co-produced between city planners, designers, and the citizens who ultimately end up occupying and using these spaces (Ahn 2016, Crowe 2016, Muthne-Kaas 2015, Palmas \& von Busch 2015). The natural world is, of course, intentionally modified in ways that might not immediately be 
considered "designing," such as using botanical cultivation rather than technical infrastructural development to make subtle changes to place. This makes urban planning a unique form of codesign, one that highlights alternative forms of expertise in constructing projects that are beneficial for many actors beyond the human world. Wildlife, plants, and the biosphere itself respond intimately to the ways in which we interact, and design, the natural world. Design makes suggestion of the world's purpose, and when humans design the natural landscape, we create road maps for how nature should be considered and engaged with.

Urban spaces are a unique type of co-design project because they are public resources, who concern incredibly diverse stakeholder groups dispersed across the public. Dense, urban city spaces can become co-designed into many different types of infrastructure, including buildings, parking lots, houses, and of course, parks. Parks and urban green spaces (UGS) are special matters of concern for the public, as one of the last remaining public spaces that do not require patrons to spend money to gain entry. They have also been recognized for the many potential benefits that researchers argue USGs provide to urban residents, including strengthening their physical and mental health (Vries et. al. 2003, Dzhambov \& Dimitrova 2014, Grahn \& Stigsdotter 2010, Xu et. al. 2017). This has made them important places of interest for city officials and planners who are concerned with themes of sustainability. Because USGs are public resources, they become hosts to complex processes of care, use, and engagement, subject to diverse human and non-human stakeholder groups that, in the face of increasing open land scarcity, must learn to co-habit shared spaces. They are thus part of larger socio-material configurations (Latour, 1985) that reflect community activities, needs, identities, and aspirations. This means that when co-designing UGSs, the range of stakeholders is typically larger than that of other co-design projects, extending, in fact, beyond the human world. 
These dynamic configurations force UGSs to adopt complex and intersectional identities that are shifting and morphing as stakeholders renegotiate their meaning between them. This is highlighted by the co-design process. The co-design of UGSs is perplexed by contesting usage practices and opposing perspectives on "nature" and the natural world, among other disputes. Co-designer's of community spaces are thus faced with a unique dilemma concerning representation. Designers have the ability to materialize the interests of certain groups, emphasizing specific site functions and interpretations, and re-prioritizing them in the process. This complicates how power interacts with contesting imaginations of "the perfect space", and challenges experts and planners to thoughtfully consider whose interests are codified into the landscape, as they legitimize those interests when assimilating them into the planning schema. Inevitably, certain actors will be able to lobby their voices more aggressively and planners will meet some ideas with greater acceptance than others. This means that the accessibility, recognition, and history of certain interest groups is built into the space from the beginning (Metzger 2013: 728). It is because of this that researchers must challenge the legitimacy of placemaking through a lens of design practices that touch on themes of diversity, equity, and social capital, which co-design is uniquely situated to do.

This thesis will use the re-development of an UGS in urban, downtown Portland, Oregon, called the Oak Savanna, as a case study to evaluate the co-design process and how it represents the interests of different stakeholder groups. Many different stakeholders habitually use this urban green space, some of whom may consider their interests oppositional. Historically, usage conflicts have manifested primarily between dog-owners who use the Oak Savanna, and other groups who have intense long-term connections with and investments in the site, such as PSU's Indigenous Nations Studies department. In addition to external stakeholder conflict between 
users of the Oak Savanna, there has also been internal stakeholder conflict between different departments at PSU who want to co-opt the space for dissimilar needs and interests. In an effort to preserve the Oak Savanna as open-space and to mitigate some of the tensions that have been occurring over the last couple years between different stakeholder groups, PSU planners decided to expand the space and re-develop it so that it would reflect community needs and offer solutions to existing conflicts. They did this through a process I will call co-design, in which non-technical experts (i.e. the public) were invited to participate in the co-creation of imaged space and bring to light a new, collaborative, community driven area with the help of design experts (Munthe-Kass 2015: 221). Here, I will interrogate the Oak Savanna co-design as an example of how this approach has been used to inspire space that represents community interests and minimizes some the "top down" effects that design can impose on communities. I ask whether various stakeholder's interests are equally represented at the Oak Savanna, how stakeholder interests hinder one another, how the co-design process addresses these conflicts, and further, represents the ideas and needs of those who use and love the Oak Savanna. Using a mixed-methods approach with focus groups, interviews, and participant observation as my primary methods and a drawing activity and archival data as my secondary methodological data points, I assessed stakeholder's interests in the space both independently, in the context of the co-design process, and in the context of the prototype images of the space generated from the codesign meetings.

In the paper that follows, I will outline my theoretical approach to this dilemma and discuss the key terms one must be familiar with to follow the Oak Savanna research project discussed here. I will explain the history of the Oak Savanna and what has prompted this research, situating its significance within the co-design meetings facilitated by PSU planners and 
designers. After explaining how the co-design meetings took place, I will delineate the methods I applied to this project to gather qualitative data on stakeholder interests in the space and experiences in the co-design meetings, including my personal methodological viewpoints for engaging others through fieldwork. I follow this up with a discussion of the results, presented in four parts, through which I argue that the co-design meetings did not ensure the satisfaction of all participants and did not equally assess how space is designed through both physical and social processes. Finally, I conclude that competing design epistemologies may be flattened by codesign facilitators that are not able to engage the complex social realities at play before co-design enters their world. I demonstrate how stakeholder groups become at risk of conceptualizing neighboring stakeholders as one dimensional and argue that if the co-design process cannot unsettle these notions through careful analysis of the present, their projections of the future may be at risk of reproducing problematic social structures rather than agonistically inspiring community learning. Through this case study, I hope to make contributions to an anthropology of co-design by relating the practice of co-design to ethnography and critical analysis of engagement with both oneself as an expert and the stakeholder as a collaborator.

\section{Theoretical Framework and Key Terms}

\section{Political Ecology}

"...design represents perhaps the most common channel through which humans intervene, directly and indirectly, in the lives of other humans. When viewed from this perspective, the moral implications of design and designing become more pronounced."

-Murphy 2016: 435

In this study, I employed a framework of political ecology to better understand how power intersects environmental accessibility and augmentation in urban areas. Political ecology considers that resources are almost never equally allocated to stakeholders as a predictable 
consequence of the unequal distributions of power in society (Escobar 1996). This dynamic is then interpreted as a debate for who should be able to influence, control, and ultimately own the natural world (Vaccaro et. al. 2013). Arturo Escobar (1999) defines political ecology as, "the study of the manifold articulations of history and biology and the cultural mediations through which such articulations are necessarily established," (pg. 3). Indeed, the 'articulations of the world' primary fall within the purview of designers, who are hired to direct, re-imagine, and reformulate the properties of the natural world into new things, ideas, and places. Designers create the conditions for which members of society move through, critique, assimilate to, and reject. More than creating things or places, designers intervene in the lives of others through their expert knowledge and practices in intimate ways that impact the everyday realities of other people. Thus, designers carry with them a moral responsibility to "the people" to create and introduce things that are useful to their lives (Murphy 2016: 435), or, in other words, to reconfigure and distribute the materials of the natural world in ways that are both equal and productive. When discussing these implication as they apply to designing landscapes, it becomes quite obvious how the power and expert knowledge of the designer intersects hierarchical engagements with the natural world.

So where does this leave the non-experts? How do the primary users of different city corridors or neighborhoods interact with these re-configurations happening around them? There is a very practical reason to why the many people who use spaces are not the same few who design them: discord. Most people have at least somewhat conflicting or nuanced understandings of place, how place should be cultivated, and what associations should be programmed into it. People develop narratives to explain their place in the world as human beings, beginning with one's initial conception of the world itself: as a biosphere, as a holobiont (Gilbert, Sapp, \& 
Tauber 2012), or as Turtle island (Kimmerer 2013). Individuals shape their mental models for navigating "the environment" through their individual experiences, histories, understandings, and personal goals. It is because they are each so unique that it is difficult to have the public cocreate shared spaces without some kind of centralized leadership.

Projects such as the Oak Savanna challenge the individual imagination to become part of the collective unconscious, highlighting the discord I am describing above. If one can vocalize their ideal space during the co-design process, they can operationalize their agency-or at least attempt to merge their needs with others in the room so that they can gain traction. In political ecology, researchers must explicitly assess who is using their agency to effect these changes to the natural world. This is why political ecology is particularly useful when evaluating the codesign process. In this space, where voices, or imaginaries, are jostling for relevance, concerns necessarily crowd out or consume other concerns. Planners know this but promise attendees something they cannot resist- recognition. When facilitators and planners of the co-design process extend their offices and laboratories into conference or rooms or "meetings" (of course, they are meeting frequently on their own), the whiff of accessibility invites guests to come have their problems solved- or at least recognized- by the magic of expertise (Latour, 1985). And in these intimate relationships, where experts literally design the world around you with or without your consent, stakeholders have no choice to take whatever opportunities for influence they can amass. There is an inherent inequality in these frameworks that "co-creation" may be able to overlook but cannot nullify.

Political ecology has the potential to help guide researchers through these questions of connection, realization, and collaboration. By explicitly highlighting the ways hierarchical models interact with co-produced realities, we can begin to unfold the processes concealed 
within them. It is not my goal in this essay to attack or dismiss the efforts of those planners and designers in power who are, after all, trying to incorporate the perspectives of people and groups other than themselves and preserve a very special space on PSU's campus. Rather, I aim to interrogate these processes of engagement, which rely on the notion that some are invited to participate while others design participation processes, whose methods have largely been ignored in the design literature.

\section{Co-design}

The format invoked by the creators of the Oak Savanna expansion project was referred to as a series of charettes (also spelled charrette). "Charette" is a French term that has received little acclaim in anthropologic literature, but that most modern architects define as a lengthy meeting in which all stakeholders connected to the designed thing work together to collectively contribute to the final product (Willis, N.d.). Ironically, the term originated as jargon used in the late 1880's by French architecture students and referred to projects they needed to rush to completion so they that they could be placed in the charette (French for 'cart') which collected them for consideration (Willis, N.d.). There have been many iterations of these kind of collaborative design models that have surfaced over the last couple of centuries. According to some, co-design differs from user-centered design or participatory design, in that in collaborates with the stakeholder, rather than merely observing or engaging them (Jørgensen et. al. 2011). In this essay, I choose to refer to these collaborative processes as co-design, much in the same way that Munthe-Kass (2015: 221) have framed the larger approach, "(co-design is) facilitated processes or interventions in which the participants work together to imagine and improvise possible future socio-material configurations in urban space." The co-design of urban space can involve literally crowd sourcing purposes for unused land via technological mediums (Crowe et. al. 2016), providing physical materials for citizens and stakeholders to create manifestations of 
their desires during "drop by" hours (Munthe-Kaas 2015), or funding user-initiated projects by powerful institutions for small scale restoration efforts (Ahn 2016). As the term grows in popularity, scholars have begun to study how the concept can contribute to the design of goods and services (Pirinen 2016) as well as urban planning. This essay, however, speaks to the usage of collaborative methodologies in creating urban spaces only. Although this collaboration can take on many forms, here I will explore the abstract properties of co-design as they relate to measuring the cohesive potential of the Oak Savanna. This, I assume, will be more productive than to interrogate the charette process as an artifact of design thinking.

Because urban cities are becoming increasingly concerned with livability, city officials must attempt to reconcile the understandings of technical experts from the planning domain with the desires expressed by community members. Users are typically quick to criticize large, beautiful, even useful structures if they impede their daily routines or long held affiliations with the site. Stakeholders may imagine designers as "coming to" the project, much in the same way anthropologists that are commonly considered by the communities in which they conduct ethnography. Their analysis can come across to those familiar with the space as crude and etic, appearing as an assemblage of quickly extrapolated facts, selectively chosen and woven together in a way that supports the agenda of the mysterious expert whose craftsmanship is not to be questioned. The smaller the scale of designed space, the greater the influence of localized understanding will need to be considered by planners and designers, and the greater the likelihood the designer is not included in the emic understanding, or "coming from" the localized perspective. Many urban planners and designers are keenly aware of the intimate connection between person, place, and even structure, that supports an emic perspective, whether or not it influences their methodologies or decisions. This makes the apparent disparities in access to 
resources or 'interests' seem to serve as greater evidence of the distance between the designer and stakeholder.

This is not to imply that all stakeholders are equal. Surely, the distance between the designer and the stakeholder will vary depending on which position they claim during the negotiation process, and the internal/external stakeholder dichotomy is riddled with shades of grey. To ignore this is to overlook that the designers themselves hold incredibly high stakes in the process, often including their credibility and livelihood. It is not that the facilitators are just lethargically dismissing the importance of public involvement in their work. It reflects well on planners and designers who are savvy and secure enough to collaborate with public stakeholders on design projects as they reveal themselves. In fact, the stakes are high for private funders, city bureaucrats, or institutional officials who oversee these projects, whose name, money, and ultimately property are on the line for the social re-invention and destruction of public projects. Of course, this is certainly not unique to the designers; everyone has something on the line during processes of negotiation and collaboration. Co-design is, after all, the product of heterogenous parts converging. In this case study, each stakeholder group- and further each individual- have varying, and in many instances, conflicting interests. The process of co-design introduces an opportunity to lobby those interests, create alliances, and voice dissatisfaction. But even within collaborative spaces, the question remains as to what type of suggested changes facilitators lend their ear to, who gets to evoke the need for change, and how change is introduced to different communities.

Urban planning experts recognize the benefits of co-design, and that it is a mechanism for bringing to light the relationships that different stakeholders share with a space. Theoretically, co-design can use the conflicting perspectives of different stakeholders to its benefit. Co-design 
embraces subjectivity and denies the idea the "correct" space is technically determined, instead using agonism to its advantage to renegotiate the social relationships between stakeholder's mental models (Mouffe 2007). Thus, co-design is unique in that it can take advantage of the intersectional identity of land (or the designed thing more broadly) and attempt to proactively mitigate conflict (Collier 2013) by creating a plurality of co-existing spaces at once (MuntheKaas 2015).

\section{Stakeholders}

The idea of co-design is of course predicated on the concept of stakeholders- the idea that there are other imaginations worthy of influencing the design process. Co-design entails establishing whose input is worth considering in the process of creation and construction and is thus consumed with the question of who is allotted the right to lobby their voice. It is easy to consider stakeholders to be the anyone who has an interest in or connection to the place in question (Agrawal \& Gibson 2001; Baker et. al. 2010) or those impacted by its renovation (Legacy 2010). But as many have pointed out, just because you have a connection to or thoughts or feelings about a place, does not mean you may know what to do with them (Healey 1998). Because of this, developing stakeholder groups to collaborate with is not merely an epistemological issue, but an ontological issue at the forefront of the co-creation process (Susskind \& Weinstein 1980). In other words, the idea that stakeholders are established by tracing connections to a place ignores the fact that they are actively created when they are imagined in the planner's and designer's (and anthropologist's) minds (Metzger 2013: 782). Metzger (2013:783) argues that because there are no objective standards for determining whose interests should be considered, that planners and designers actively, "gener(ate) and fost(er) stakeholders by manipulating the interests and attachments of actors through the reality-crafting practices." Being implicated by these changes is thus not a given, but a learned behavior (Marres 
2005) that can only truly come to light and become operationalized into 'matters of concern' when actors are granted agency (Latour 2007).

\section{Context: The Urban Oak Savanna}

Living in downtown Portland, I often hear visitors from other cities in the Western United States express their appreciation for the amount of green space incorporated into PSU's campus. A man from Berkeley once told me he attributed his attraction to downtown Portland as a byproduct of the built environment being tightly interwoven with green space throughout the city, describing it as "an oasis." In actuality, downtown Portland, Oregon is a highly urbanized area that has faced the dilemma outlined above; and each year downtown residents are rearranging their mental maps, re-orienting themselves toward whichever new, little green space has become available in the wake of the latest development. In more recent years, PSU developed what they call an open-space plan to address the issue of rapid expansion and development on campus. To summarize, the plan essentially attempts to preserve a certain percentage of green space on campus in an effort to ensure the university landscape is "multifunctional," regardless of whatever developments they are currently invested in (Portland State Univeristy, n.d.). An understandably difficult task, seeing as new renovations are consistently under way, updating and expanding a development plan whose legacy began in the 1950s (Portland State University, 2016).

The Oak Savanna, a constantly changing space whose definition is difficult to pin down, is an open-space located in the middle of campus, and, consequentially, in the middle of downtown. The Oak Savanna project involved seizing an area of green space on campus that became available after having held construction equipment for a neighboring development project in 2010. In Fall of 2011, students requested that the construction company, who cleared 
the equipment after completing their work, and landscape facilities introduce native grasses, Oak trees, and services berries (also a native plant) into the space. The following year, students and faculty from the Indigenous Nations Studies Department (INS) and Native Center blessed the area, and it was recognized as a place that is "dedicated to the relationship between the First Peoples of the Pacific Northwest and the native vegetation of oak savannas" (taken from the Oak Savanna "Dedication" statement, found in associated documents). PSU's Student Sustainability Center (SSC) also adopted the space and assisted in the INS blessings and ceremonies, advocating for the Oak Savanna to be recognized as a designated greenspace by the university in Fall of 2014. The SSC developed a formal mission statement for the space as one of the primary advocates and co-managers: "The Oak Savanna is a minimally managed outdoor classroom that shares the natural history of the Pacific Northwest, offers a place for reflection and healing, creates wildlife habitat, and demonstrates Indigenous land practices for food, medicine, art, and ceremony."

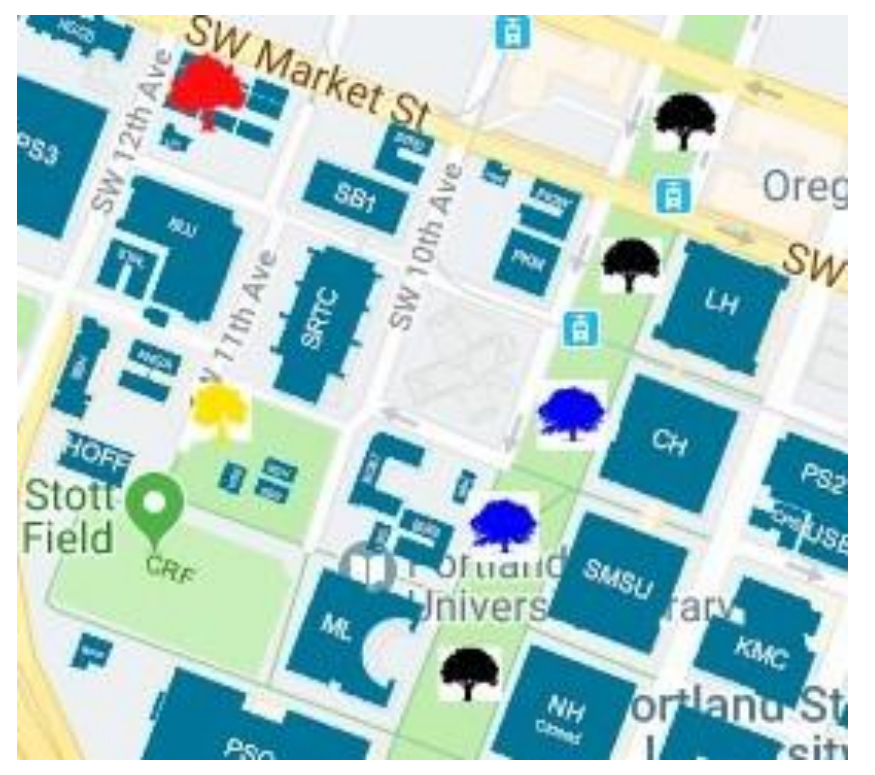

Figure 1: A map of the downtown Portland featuring urban green spaces in the center of campus. The Oak Savanna's location is marked by the yellow tree. The red tree indicates a green space owned by PSU that was developed in the last year, and the row of black and blue tree indicate the Southern Park Blocks, a UGS owned by the city.

Despite the efforts from multiple student and university groups, formal greenspace "designation" from the PSU administration never came, and in fact, informal negotiations about 
what the space should be and how it ought to be used continue to occur to this day. To begin, the University itself has contested notions of the Oak Savanna as a green space, particularly by filling the site the construction equipment again around late 2015/early 2016, this time only occupying the left half of the site. It was gated up, and trailers with equipment for different campus projects were placed behind them. This was contradictory to the goal of facilitating open space, particularly open space that mimicked the natural landscape. Soon after being established, the Oak Savanna was also inundated with canine activity, much of which leaves behind unsanitary fecal matter that goes "unnoticed" by dog owners. In addition, neighboring student housing units have held certain events or celebrations in the space, PSU childcare facilities use the Savanna for outdoor learning, and neighbors can often be found lounging in the sunlight. The space is also educational in nature and is commonly used as an outdoor classroom or space for ecological research. As my friend Barry once described it to me, the area is an "ecological theater" with a shape shifting identity, able to conform to many uses and needs (Dunham, 2017).

When part of the Savanna was blocked off for the holding of construction equipment, the competition to use the redacted, smaller section of land fostered tensions between different stakeholder interests. Newly erupting camas bulbs are trampled by furry, four-legged friends before the brilliance of their coiled purple flowers are even given the chance to unfold. Recreation may displace the elders, who search for limited opportunities to comfortably sit under the shade. PSU's daycare facility brings the children to the savanna to build confidence in the outdoors among youth, but all the while their supervisors must protect them from bikes whizzing around the periphery, wandering canines in search of an unmarked bush, and the cigarettes buts that decorate the dusty, brown spots of the savanna floor. The relationships stakeholders and users share with the savanna generate varied interests; it is clear that not all of the Oak Savanna's 
gifts are interpreted and valued equally. Stakeholder groups have historically had problems not stepping on one another's toes.

None of these uses necessarily detract from formally recognizing the Oak Savanna as open space, but they do show how the space is considered multi-functional, and its identity is intersectional, at the expense of not having developed agreed upon uses between stakeholders. In June of 2017, the trailers were finally removed, along with most of the biodiverse species found at the Savanna. For whatever reason, it was mowed down almost completely. Maintenance plans for the space are collaborative and change over time as relationships between departments on campus wax and wane. From time to time the Savanna is mowed down, but this is uncommon and typically discouraged by the INS community. In addition to the Oak Savanna's bioregional affiliation with indigenous communities, it hosts several plants that are important for various cultural reasons, which complicates the relationship between the landscapers, INS community, and dog owners, among others. In addition to some of the pressures on the land I've briefly explored here, developers working with PSU's newest flashy, attraction, a "Pavilion" building, want to co-opt the Savanna as a natural entryway to their facilities.

PSU planners working on the open space plan are pushing against these efforts, trying to protect the space from PSU higher-ups who see it as prime site for development- land that would be free for the university to build on because it already owns "the property". The fact that it was never formally recognized as a greenspace by the university complicates their work. The Open Space Plan attempts to address these threats to the Oak Savanna (and other, similar threats to open space on campus) and has been in the process of development for at least three years. Although the Open Space Plan is still waiting to undergo review by PSU development board, the planners choose to begin exercising efforts to save the Savanna in Spring of 2017. At this time, 
the planners funded a public re-design project for the Oak Savanna. They announced that they were going to host design meetings open to the public, called charettes, bringing together the different stakeholder groups to co-design and revise the space, collectively imagining what it could be. The meetings invited stakeholders to come express their concerns about the current space and suggest interests they would like to see incorporated into a re-designed version of the Oak Savanna. They aimed to use the process of co-design to facilitate a community created area, cultivate public investment in the site, and offer the users public ownership over the re-invented space.

These co-design meetings are referred to by the planners as a study, as well as a visioning exercise. What they are not referred to as is a planning process. PSU planners have engage the public about development decisions through thought experiments before, primarily through the open space plan. The Open Space Plan also claims itself as a study. One of the planners proudly recounted to me that the Open Space Plan stakeholder engagement process was,

...nearly 2 years and extensive. There were 1 hour long focused discussions with specific and open-ended questions with faculty, students, staff, and community members. These meetings led to our primary recommendations as well as our guiding principles, and framework for the plan. There are parallels here with the co-design meetings. According to the planners, the co-design meetings were the foundation of design work that may or may not occur in the future, depending on funding. How fitting the word "study" is for this process cannot be verified, as the methods nor resulting data was never released publicly.

Although it is a visioning process, and not a planning process (according to the planners), many of the planners who advocate for the space believed the co-design process was valuable in that it would decrease the likelihood that the area would be developed in the future. What was to be the result of these meetings was not explicitly announced, but five "prototype" images were 
generated from the meetings, designed around the input provided from the co-design process (see Appendix B). Thus, these prototype images are emblematic of the processes happening inside the co-design meetings. They are one clue as to how information circulates, exchanges, and processes in these arenas. Indeed, if the administrative advocates can continue to collect funding for the Oak Savanna co-design project, they will actualize the re-design when possible, likely along with some additional research. I do not believe it is too far a stretch of the imagination to assume that the reconstruction process would be at least be somewhat influenced by those prototype images and "visioning" processes resulting from the co-design meetings, thus making them worthy objects of careful observation and evaluation.

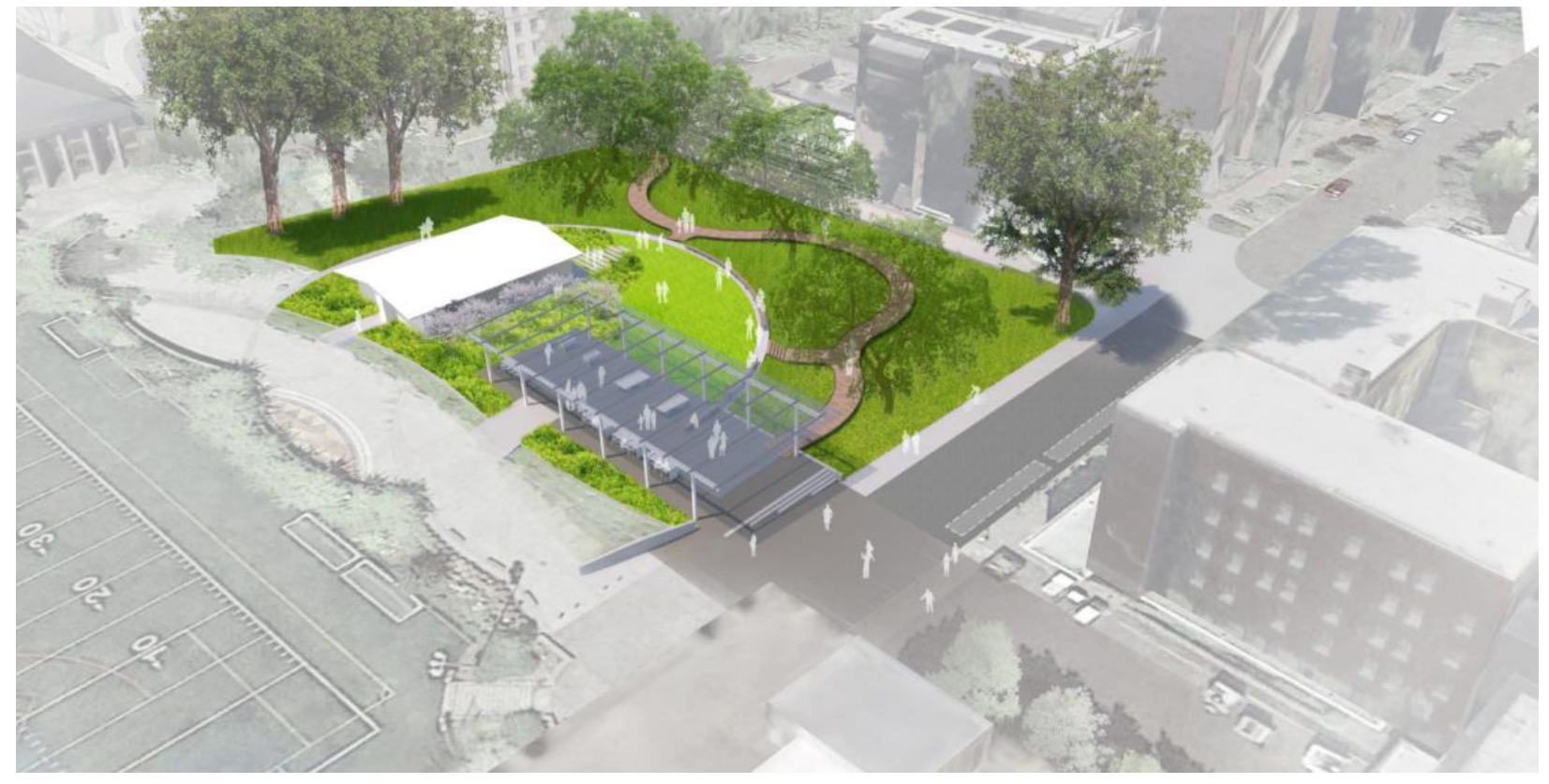

Figure 2: First of the five prototype images listed on the website of the design architects contracted by the planning team to facilitate the co-design meetings. The remaining prototype images can be found in Appendix B.

However, the larger design processes occurring outside of these three co-design meetings are also influencing the space, grounding the meetings as only one iteration of co-design process. PSU planners and their contracted designers (as well as some key student and faculty leaders) 
held meetings before the three co-design meetings took place, which set up much of the premise for how they would occur. My informants who are PSU planners assure me not to place too much emphasis on the prototype images generated from those meetings, reasoning that if the project can receive additional funding, they will likely engage in another round of co-design. This is because, in their view, these initial co-design meetings (being evaluated for this study) were merely chances for the community to come together and really consider how the space could be re-imagined to address conflict and solidify its place in social memory as open land. Thus, the images produced from these meeting were perhaps only drafted to "inspire" rather than act as the road map for developing the new Oak Savanna. This only highlights the relevance of this study. If the co-design process will occur again, the designers, planners, and administration who oversee and construct these processes can use the analysis here to inform future iterations of the co-design process. This study will evaluate the co-design process iterated in those three meetings, which has proven to be a very unique form of engagement from the larger design processes they sit nestled between. I aim to understand how stakeholders see their input as being heard, not heard, or re-interpreted through the prototype images produced by the designers as a final product of the co-design process.

\section{Methods}

This study employs a mixed methods approach to investigate the research questions posed above. My primary methods include semi-structured, open-ended focus groups, key consultant interviews (Schensul \& LeCompte 2013; 174-179), and participant observation. I will "check" the primary data from these methods against the data collected from my secondary methods (Schensul \& LeCompte 2013; 80), which involve using artistic expression as a way to elicit opinions on design and searching archival documents from various departments at PSU. 
The documents included e-mails, historical data on the block where the Oak Savanna is situated, formal documents passed through the university and associated contractors, meeting notes, and more. Different participants shared these documents with me and I have permission to use them to inform this study. The secondary data points provided through creative design and historical records have helped me to further understand the primary data provided through interviews and participant observation. For this study, I selected participants via quota, convenience (Bernard 2002; 181-184), and reputational sampling (Schensul \& LeCompte 2013: 285) to ensure the study captured multiple perspectives from different stakeholder identities and communities. This meant that individuals were selected based on whether their point of view was already represented in the study, recommendations about who should be involved from individuals already participating in the study, and, of course, an individual's availability and willingness to participate in the study overall. In total, I facilitated one focus group, consisting of three participants, as well as three formal, key knowledge holder interviews. The results of the four total group and individual interviews and their accompanying artistic creations, as well as the qualitative data from the participant observation, have informed the results of this study. The results were analyzed using line by line analysis (Khandkar 2009) and inductive content analysis (Bernard \& Ryan 1998: 625) to pin down emerging themes, and ultimately results, for this study. Because this study is heavily informed by personal relationship to the research, I adopt a standpoint epistemology to respond to the perceived risks generated from my subjective perspective and close emotional proximity to the project.

\section{Focus Groups \& Interviews}

In order to understand group stakeholder's ideologies, preferences, desires, and interests, I held focus groups and interviews with leaders from the different stakeholder communities being examined here. These individuals each have each articulated their relationship to the Oak 
Savanna differently in terms of personal, structural, and policy connections. The also had different relationships to the co-design meetings, which varied based on attendance and extent of participation in both the meetings and larger planning processes. I recruited participants based on the knowledge I accumulated about the project in three ways. Preliminary research allowed me to identify key players by reviewing policy practices implemented around the area in the past. These individuals were purposefully asked to participate because of their long-term engagement with the savanna. Additionally, existing stakeholder's and participants in this study were asked to suggest the names of other important leaders or stakeholders associated with the Oak Savanna's historical or current management in a sort of reputational sampling (Schensul \& LeCompte 2013; 285). Finally, I produced promotional materials for Oak Savanna interviews and focus groups (see Appendix C) that I handed out to those who I witnessed using the Oak Savanna while conducting participant observation, during which I briefly overviewed the interview process. More broadly, I used quota and convenience sampling (Bernard 2002; 181184) to generate interest from at least one individual per stakeholder group being evaluated for this study, including the users and managers of the Savanna as well as the PSU planners directing and facilitating the co-design process.

Because individual users and caretakers of the Oak Savanna largely share attitudes with others in their stakeholder group, I facilitated a focus group with individuals who belonged to the same stakeholder position only. The focus group, which contained only dog owners, was the only interview process that was not engaging targeted leaders of a stakeholder group. Instead, the members of this focus group simply identified as being included in and/or adjacent to the dogowning community formed around the Oak Savanna. By contrast, I also organized individual interviews with leaders from different stakeholder groups to gather more in-depth data on 
different stakeholder group perspectives. Although these leaders also certainly cannot incapsulate the complex relationships each person develops with the Oak Savanna, they represent the dominant attitude of those who share their usage or management perspective. The role of interviews grew in importance when I realized many individuals had unique holistic perspectives, considering themselves members of many different stakeholder groups at once. These individuals are key knowledge holders keenly aware of much more than the interests of one stakeholder group. I felt that placing these individuals in focus groups with reified stakeholder identities (i.e. dog owners, or policy makers, or indigenous rights activists etc.) would not encourage them to share that holistic perspective.

Over the course of ten weeks (during which I conducted, analyzed, and transcribed this study) I organized one focus group and three formal interviews. As mentioned above, the focus group included three dog-owners or individuals who consider themselves involved in or adjacent to the dog owning community (an occasional dog walker or caretaker, or a close friend of someone who owns a dog and knows the Savanna through the lens of a "dog park".) Each of the three solo interviews engage a leader from a different stakeholder group. I conducted one interview with a PSU planner who facilitated the design process, who occupies the highest link in the chain up toward PSU bureaucratic centralization in this study. Another participant is a student leader from PSU's Student Sustainability Center (SSC), an organization also allocated some agency over the Oak Savanna. The final interview participant is an indigenous student leader in PSU's Indigenous Nations Studies (INS) community, a community that has largely reclaimed the space for their interests since the Oak Savanna "project" was conceived. These six participants described their relationship to the Savanna in very diverse ways, including student, managerial, historical, cultural, advocacy, professional, stewardship, and usage relationships. 
Together these six perspectives have informed the line-by-line analysis of utterances (Khandkar, 2009) contributing to the qualitative data for this study.

I asked each interviewee (including the collective focus group) the same list of questions (see Appendix A). The first nine questions inquire about the participant's relationship to the Oak Savanna, their interpretation of it currently, and what they enjoy or do not enjoy about the space. The next 8 to 12 questions are designed to elucidate the co-design process, their observations on those meetings, and what interests were expressed in that context. The number of questions I asked each participant varied depending on whether or not they attended the co-design meetings. If they did attend the meetings, I asked them an additional 12 questions about the process; if they did not, I asked an additional eight questions about what they would have wanted to express in those spaces. During this "second section", I also provided participants with the images generated from the co-design meetings and asked to respond them (see Appendix B). I employed a semi-structured approach so that I was able to ask follow up questions, or create tangential questions, to better understand and contextualize former responses. I used these "impromptu" questions sparingly, and they primarily followed the themes of the pre-written question script and the emerging themes within responses. All interview and focus group participants were sent the pre-written question list by me before hand, along with an informed consent document unique to this study (see Appendix D) so that they could have a significant amount of time to review them and ask any clarifying questions prior to the date of the interview.

The reader should note participants sometimes asked me, as the interview-er, questions during the interviews. I suspect this is because many users and lovers of the savanna (particularly those that were directly involved in the co-design process) were not made aware of any 'updates' following the renovation process. Thus, participants would frequently ask me questions about 
elements of the upcoming space and my personal opinion on them due to my ongoing research interest in the area and my own stakeholder affiliations. It is possible that these questions could have informed the opinions they expressed. This reciprocal approach to ethnographic engagement was used to both build trust and diminish the feeling of extraction and paternalism that has been noted to accompany anthropological interviews (Clifford, 1986; Mascia-Lees et. al. 1989). As the researcher, I encouraged all relationships and perspectives to be shared and tried to meet them all with acceptance and empathy.

\section{Drawing it Out}

Using art to express interests provides another outlet for communication that is perhaps more abstract and less limiting. As a secondary method, the last three questions of the interview process ask participants to draw their ideal PSU urban Oak Savanna, explain their design concept, and compare their creation's to both one another's as well as the final prototype produced by the co-design process (again, see Appendix B). I provided paper, markers, colored pencils, and crayons for participants before asking them to draw out and visually represent their ideal space. This is a common method employed by designers working with stakeholders on projects, which I am borrowing for shifted, anthropological purposes (very much in line with what Gunn \& Donovan 2012 have called a 'design for anthropology'). Using artistic expression in ethnographic settings is useful for overcoming language barriers and creating a unique kind of record of the research. It also allows interviewees a different form to organize their thoughts and prompt additional feedback as it naturally emerges from these processes (IDEO, 2015:65). Using a creative secondary method helped me visualize the interests of each individual being interviewed, and by comparing them, the interests of each stakeholder group became increasingly clear from their over lapping qualities. I saved images of the drawings and eventually considered them to be primarily qualitative data, as their accompanying explanations 
were much more informative than the drawings themselves. I analyzed the images as part of the inductive content analysis process.

\section{Participant Observation}

Another primary method that I used to balance data gathered from the formal interviews was participant observation. I have been visiting the Oak Savanna regularly (never less than once per week) over the last year and a half. Within the confines of this study, I interacted with about 30 individuals in the field. These interactions were spontaneous, unpredictable, and took place in a number of locations, including the Oak Savanna, different PSU offices, and certain PSU classes and presentations regarding Oak Savanna content. Participant observation allowed me to see how the Oak Savanna was being used in real time, as well as how it was being talked about and reflected upon outside of the space. During participant observation, those individuals being engaged with were made aware of the study and gave their verbal consent to have the information and demonstrations they provided included in this written document. This information is also considered qualitative data, and was recorded by taking field notes, which were then incorporated in the inductive content analysis, further described below.

\section{Data Analysis}

To analyze the data I collected for this study, I used inductive content analysis. Analytic induction is the process of constructing explanations of larger social processes and ideas through careful analysis of individual narratives (Bernard \& Ryan 1998: 625). I initially reviewed qualitative data by fully transcribing the interviews and focus group and analyzing them line by line before grouping utterances by concepts or themes that reoccurred (Khandkar, 2009). Because I employed the same list of questions for more than one participant (the amount of which depending on whether they attended the co-design meetings), I was also able to group different participant responses by question. This allowed me to see themes emerge from specific 
promptings I provided. From these themes, I composed an explanatory narrative that is congruent with each account. I continued to shape and morph this narrative, or conclusion, until it could account for all data collected, including the drawings I asked participants to complete. When possible, I provided participants excerpts of the unfinished thesis that included their quotes and contributions so that they could verify that the way the information was being used was true to their intentions when sharing it. This minimized the opportunity for my bias to interrupt the narrative that we were co-constructing and increased the clarity and accuracy in the results section that follows.

\section{Epistemic Starting Points: Reflexivity \& Positioning}

Feminists, anthropologists, and social scientists more broadly have long problematized the idea that science is an objective practice that does not, and further cannot, be influenced by the individual experience, particularly as it applies to these overlapping disciplines (Clifford 1986; Mescia-Lees et. al. 1989; Rosaldo 1993; Tuhiwai Smith 2013). Rather, experts who write about the experiences of others to produce new and novel insights are recognized as having epistemic privilege- in other words, they are granted the agency to repackage the lived realities of others through their own lens creating knowledge that is "demonstrably limited" (Naples \& Gurr 2014: 22). The abandonment of objectivity highlights the role of intersectional analysis in social science and asks researchers to critically examine the privileged social locations they possess before engaging the populations in question. Thus, this study aims to adopt a standpoint framework (Harding 1986) methodologically to situate my knowledge within my own experiences, as they are important and informative to the ways in which this research has unfolded. 
My relationship to the space was cultivated by visiting the savanna with my dog, who I would argue also has an attachment to the site. I became integrated with what I refer to as the dog owning stakeholder group, as we shared an interest in the space and saw each other often enough for both us and our dogs to develop relationships. Because I shared a relationship with the space long before I began approaching this topic from the vantage point of 'researcher,' I attended one of the co-design meetings last year out of curiosity (these are not included in the study as participant observation, as none of the preliminary research is included for the results of this study). I also encouraged others to attend the meetings who had not heard about them (as I myself only stumbled upon the meetings serendipitously). I was not silent at the meeting I attended. I expressed opinions, advocated for personal interests, and engaged not as a researcher, but as a concerned citizen. For me, this study is attached to very personal interests. Both me and my dog are stakeholders in this process. I also care deeply for many of the other stakeholder groups (and their interests) with whom I share personal relationships with.

Although these human relationships introduce an obligation to carefully examine this issue at hand, the gifts that the Oak Savanna has given to both myself and the larger community cultivate an even greater sense of responsibility. It is worth re-iterating for those reading, many whom I know share a relationship with our faceless friends living at the Oak Savanna- I do not write this essay to penalize planners or designers for their time, passion, or dedication. I write because I believe critical thinking is one of the primary ways I feel I can advocate on behalf of the Oak Savanna. It is not right to think of her as a designed thing. She carries values and knowledge and stories, not imposed by the cultural geometry of design (Murphy 2013), but inherited by a life of hardship, fighting off development and a desire to be reunited with the heart of her city- the love of the people. I write because I am indebted. The Oak Savanna has given me 
so much- she gives me community, friendship, a place to relax, a place to laugh or cry or uncoil or connect, a symphony of teachers to watch and learn from, a healing breath, and a situation from which I can begin academic pursuit. Most importantly, she has given me responsibility to protect and tell the story, as well as I can, of the people who love and care for her. This essay is not intended to paint the designers and experts facilitating the co-design process as villains or dismiss the advantages of using co-design. Rather, it interrogates the ways in which different social actors work together to negotiate concepts of place, and what processes complicate these relationships.

\section{Results}

\section{Raising the Stakes: A Narrative Portrait of Savanna Relationships}

In order to understand what different stakeholder interests are, the study began by engaging participants about their existing relationship with the Oak Savanna. I untangled the web of overlapping and often intruding interests by stakeholder groups surrounding the Oak Savanna slowly during interviews and participant observation. Participants painted the area as a safe, uplifting, or even as a sacred place to gather with friends and loved ones, while simultaneously describing a space of conflict, opportunity, misunderstanding, and struggle. To better understand how the Savanna can operate under these two imagined frameworks, this initial section will review the Oak Savanna's purpose, what it offers the community, how stakeholders imagine one another, and how those imaginations converge to create spaces that are simultaneously controlled and chaotic. In this first section, I argue that stakeholder's different and seemingly opposing relationships to the Oak Savanna manifest through conflicts that play out in charged moments during which stakeholders reify divisions between one another. These conflicts also manifest through smaller design changes to the Oak Savanna, not implemented by expert designers or planners, but through stakeholders themselves, as they subtly make changes to reclaim the space 
for their preferred uses. I show how these micro-negotiations of place create new spaces in which stakeholders may test authoritative boundaries of both formal managers of the Oak Savanna as well as those of other stakeholder groups.

Identities, Histories, and Conflicts

There may be a dwindling number of neighboring USGs in downtown Portland, but the Southern Park Blocks are easily one of the most memorable open spaces PSU claims in the center of campus. However, participants explained that the Oak Savanna is unique to surrounding USGs for a number of reasons including location, community, and atmosphere. Some participants noted that the Oak Savanna felt less "centralized" or "crowded," and even indicated that they felt like it is perhaps more their own. The perception that the space is more secluded and less visible to the public was shared by a number of participants, both young and old. During participant observation, some elders reported that the Oak Savanna felt specifically more accessible for elderly folk than the park blocks because the savanna is further away from the centralized areas of downtown (or near businesses) and thus, in their perceptions, less vulnerable to potential disruptions. One participant, a young woman, added, “....it feels so safe over here. So removed...People here can be awful and creepy, and this is a nice little [escape]." A number of dog owners also reported feeling as though their dogs were safer using the Oak Savanna than other UGS in the area because it is currently not directly exposed to a road in any direction. An emergency pole (a pole with a button on it that signals for PSU Campus Public Safety Office) also sits near the edge of the Oak Savanna; a couple of participants stated that the emergency pole reified their idea that the Oak Savanna was a safer space than the Park Blocks.

Descriptions of the space as safe are accompanied by short narratives imagining the Savanna as quiet, reflective, meditative and serene. Four of the six formal interview participants 
described the space in relation to their mental and emotional condition, or their "mood." One participant noted that being at the Oak Savanna made her feel as though she did not have a desire to engage with her regularly used electronic devices and that it encouraged her to be present. Another participant helps elucidate those connections between the Oak Savanna and being more aware of one's self, attributing their attraction to the savanna to "the sense of place there.." The idea of a sense of place, or an intimate, or ethereal feeling, that inspires one to engage in a new, and perhaps more contemplative way, was reported by many who interact with the space and is frequently described in tandem with the perception that the space is somehow separated from the fabric of chaotic downtown life. The benefits this perception provides users of the Savanna is that they too are safe, secluded, or in their own territory. Another participant, an INS student, supported this idea by providing a brief narrative to convey the serenity she feels in that space: "I like just like sitting there for a moment. Or [I] like going underneath the really big tree that's there and just standing there and looking at it from that perspective. Just like a nice spot to calm yourself." This example shows an instance in which the participant identifies with place (in this instance literally embodying the land) to inherit the perceived notions congruent with that area: that it is a quiet, or secluded, spot.

In addition to the associations of peacefulness and mindfulness participants expressed that they attached to the Savanna, some stakeholders, namely those of the INS community, saw the savanna as a sacred space. The cultural significance is best explained by one indigenous student leader who was involved with creating the Oak Savanna from what was formerly an unnamed field:

We were doing a project called Killapie Camas really concentrating on harvesting of Camas in a traditional [indigenous] way. We had an event at the Native Center and we really wanted to showcase the continuation of culture, of traditional ecological 
knowledge. So, we had our boss donate three of the oak trees and me and my group and a bunch of community members went out to Quamash Prairie... and we harvested probably about 100 camas bulbs. And then after our presentation at the Native Center, we went down and we planted the three oak trees and all of the camas into the Savanna.

This excerpt offers some insight into one of the situated histories of the Oak Savanna and helps to better understand what stakeholder interests are and what inspires them. Here, the participant demonstrates that those associations with the space as sacred, serene, pure, even shielded are intentionally acknowledged by cultivating a space of ceremony and cultural celebration by certain stakeholder groups. These aspects of the space still ring true today, which is echoed in the accounts outlined earlier above.

One may juxtapose Oak Savanna associations of serenity and remoteness with enthusiastic reports from all accounts of community, gathering, and human connection. Indeed, for those who participated in this study, one of the Oak Savanna's greatest gifts is not how much it can remove you from fast-paced world of downtown Portland, but how easily it can help one re-establish connections within the community. Many participants described the Oak Savanna as an access point for long-term friendships, intergenerational relationships, or even income resulting from employment opportunities established through socialization. ${ }^{1}$ Interestingly, it is the dog owners (imagined by this researcher as a "stakeholder group") who seem to experience these spontaneous associations most intensely. Dog owners described the space not only as a dog park, but also as a meeting point for other dog owners or caretakers. As one person puts it tersely, "[It's] where I go to meet up with the other dogs...I tell neighbors frequently to come here too and use it as a dog park," while another expands on the significance of the Savanna's potential as a facilitator of community:

I've meet so many people just hanging out. It's just very peaceful...there was a new person that had a dog and I was like, 'Oh, have you been over here to the dog park?' 
Cause that's what I call it. And I walked her over and showed her. I just think it's such a lovely community-it brings the community to PSU.

Dog owners, accordingly, describe the space as not being exclusive to the PSU student body or associated personnel. They seem to appreciate the accessibility of the space and the fact that it does welcome families or elders from the neighborhood to convene with students or faculty in the Savanna. These relationships clearly extend beyond neighborly familiarity; when asked what they do while at the Savanna, one participant chuckled before responding, "I have lengthy life conversations with [an elder]..every day.” The focus group conducted for this study took place at the Savanna, and during our time together, participants would frequently break away from our conversation to identify both dogs and humans playing or resting nearby. The stakeholders would interrupt their own responses with exclamations of, "Look! There's Timothy and his dog Buddy! I haven't seen them in a while..." Most of the individuals they recognized were not PSU students of affiliates. Some reported having met romantic partners at the Savanna while others proved their emic familiarity by easily naming each dog that cut across the Savanna during our hour together interviewing. The focus group actively demonstrated the community function of the Savanna dog owners have taken advantage of, as I recorded (a recording which had to be stopped three times to accommodate the three friendly neighbors who approached the group to say hello.) Unsurprisingly, when asked what their favorite element of the Oak Savanna is, one focus group participant responded, "Accessibility... it just feels very comfortable to be around and I feel like its pretty easy to get to.”

It is worth noting here that the dog owners do have an exclusive understanding of the Oak Savanna as a gathering site. Indeed, the Oak Savanna was intended to be an area that facilitated community in its inception. One student leader from INS explains, "I actually really do like the fact that a lot of dog owners will congregate and be together in a little circle while their dogs are 
playing. I actually really like that aspect because its a gathering area and its meant for people to gather together and talk and converse." Again, in this participant's initial explanation of the Camas and Oak planting that brought the Oak Savanna to life, they discuss the vital role community plays in the development process. Representatives from both groups depicted a space that welcomed neighborhood and community members in addition to PSU students. Some respondents even addressed the specific benefits of a non-exclusive space more directly: "I think it brings a lot of people that aren't PSU students to the campus. And I think it's cool because... with that you get people of different ages, and so you have cross-generational relationships, which I have had personally.” Although the concept of remoteness, removal, and serenity may seem paradoxical or incongruent with ideas of fellowship, gathering, connection, and community, the Oak Savanna illustrates how these realities easily become entangled. However, as I will argue in this next section, these associations are subject to being re-imagined during periods of contest, cohabitation, and animosity.

Although some members of the INS community at PSU appreciate the ways in which the Savanna graciously facilitates feelings of community and human connection for dog owners, most recognize the intense presence of dogs at the Savanna as a threat to many of their interests. The most vivid example of how dogs endanger cultural affiliations with the site comes from another INS student who participated in some of the ceremonial plantings in year's past:

I think that there's a big tension between the dog owners and the Indigenous Nations Studies classes... I've done two sacred plantings there where we took Camas, a traditional food, from Quamash Prairie and we planted it in the Oak Savanna. One of the times we we're planting it- it was supposed to be a sacred ceremony- a dog started running through and ripping out the camas bulbs, like, as we were planting [them into the ground], and students started crying... Then, a few days later in class someone said, 'Well, all the trees are gone and all the plants are gone already from the dogs tearing them out.' And people were crying in class. 
In this example, the student illustrates the potential consequences of dog owners using the Oak Savanna who may not, and typically do not, understand the cultural significance of the site. In this instance, even when it is being demonstrated directly in front of them. I do not say this to demonize the dog owners as careless or insensitive individuals, who are simply unaware of how to recognize these models for indigenous engagement with land. It is true of almost every dog owner that I have told this story to- they have never heard it, nor do they even recognize the Oak Savanna as being shared with the Native community at PSU. Cultural miscommunications at the Oak Savanna may manifest as incredibly charged and uncomfortable moments for parties on either end of the social transaction, often without realization of what has even occurred between the two. However, they may be understood and codified as the signature of indifference being levied against other stakeholder groups. It is more than a problem of stepping on one another toes or not having enough space to accommodate the needs of the many at once. You can imagine the animosity that may result merely from having a space that one user group considers sacred and another considers a recreational area. As one student succinctly put it: “...there's a certain way you treat something when it's essentially holy."

But dogs and dog owners are not likely to re-locate any time soon. In fact, as dog owners who participated in this study explained, this stakeholder group uses the space most frequently, reporting that they visit the savanna daily if not multiple times per day. When asked their observations about the Oak Savanna, they confirm one another's suspicions, that it is primarily, if not solely, used for dogs. Of course, they do recognize that the space is shared with students, but the sections of space that students use at the Oak Savanna (according to dog owners) are segregated from the larger parts of the Savanna dog owners reported as being "basically a dog park." Unsurprisingly, when asked how the area could be improved, most dog owners responded 
that designing or managing the space in a way that is more congruent with its dominant uses would improve dog owner's opinions and feelings about the space. Considering that preliminary research has showed that the association of the space as "PSU's Oak Savanna" is almost nonexistent (Dunham 2017: 15) dog owners have re-imagined and re-claimed a space that they saw as an ideological vacuum.

Dog owners are not simply drawn to the space because they believe it to be waiting for companionship. Dogs have regular and pressing needs to be outside and socializing with other canines, needs that are not easily met in the city. Dog owners reported using the Savanna for their interests because it is one of the only places downtown that is protected from nearby roads and vehicle traffic. The tensions described in this section have brought to light the city's responsibility to provision for the needs of urban canines, and PSU planners as well as INS students discussed various possibilities for providing a designated, gated dog park area elsewhere on campus during their interviews. One PSU planner explains, "I think a lot of the dog use in the area is not really from residents of PSU... There's no place dog town for dog owners...there's no off-leash dog place, which is not PSU's problem to solve- that's a city park issue. And I think there are creative places for that but they're not on the PSU campus." Others lamented PSU's unwilling attitude to engage an issue they saw as very much a product of PSU functioning and daily life. Although PSU houses many disabled students with service animals, or students they have allowed to have pets, they have not provided any designated areas to address the needs of those animals. Most planners and management faculty agree that a dog park on campus is long ignored and pressing need but concede that the Oak Savanna is not the right place to accommodate it. 
Yet dogs and dog owners continue to use the area, regardless of who gives them permission. And while some children or international students on campus may not be as excited to have to come into contact with dogs at PSU, much of the student body welcomes them with open arms. The student who told the story of the dog interrupting the Camas plantings continues: “...even knowing tension. I love seeing dogs if I know they're not directly tearing up the plants." Some student participants reported that seeing the dogs help improve their mood or emotional condition and acts as an "ice breaker" for making more human friends in the community. During my time at the Oak Savanna, I frequently witnessed one dog and dog owning pair arrive and take their time walking across the Oak Savanna, only to be greeted by another dog and dog owner who had found their way to the space. The two dogs would then begin to play with one another, and the humans would sheepishly follow suit, chatting about which brand of harness they preferred or where they lived around the neighborhood. Patterns of socialization that are dependent on Oak Savanna usage help to further uncover how and why dog owner's refuse to "take their business" elsewhere.

However, the INS community maintains that they create hazards for the space, and in some cases, deny that the Oak Savanna should accommodate alternative uses whatsoever. There efforts to subtly (or not so subtly) suggest that the space is simply not intended for that use have largely been ignored by other stakeholders, and university staff who have not responded to requests to re-locate doggy bags or indulge other suggestions. In addition to these conflicts, a number of tensions between different stakeholder groups have arisen since these two stakeholder groups integrated into the savanna. Another student from the SSC involved in long term planning processes surrounding the Savanna explained that conflicts that arise between the INS 
community and the dog-owning community may begin to implicate other, peripheral stakeholder groups.

...there was a temporary fence put around the Oak Savanna to protect the plants and figure out what was going on with the management, then someone cut like a dog sized hole in the fence and let their dog go in it. So yeah, I think that that was really offensive to landscaping, the student sustainability center and indigenous nations studies...

Initiatives by the INS community to protect and further the botanic growth of the Oak Savanna and how it failed at the hands of determined competitors for space. Dog owners, who likely felt rejected and isolated by the gating off of much of the space, reclaimed their "right" to be there by defying the efforts, and making their own accessible channels to the space. In doing so, they have created tensions between their community, the INS community, and the management communities in between them. The Student Sustainability Center is another group that has been granted the agency to oversee and manage the space by other stakeholder groups, often working in tandem with the landscapers (also referred to as "facilities") to create a management regimen for the Oak Savanna. By cutting the hole in the fence to publicly declare their interest in the space, the dog owners may have created divisions between themselves, and these governing stakeholder groups as well. This is only one example; during my research, I heard many stories of conflict that arose between every combination of stakeholder groups involved, and associated examples for how they manifest.

\section{Competing Models, Converging Systems}

The many different mental models, or modes of engagement, employed by different stakeholder groups who share relationships with the Oak Savanna, are largely informed by one's usage needs, historical relationship, and cultural affiliations. No subject brings to light the competing perspectives on the Oak Savanna more so than the ecological maintenance of the space. It seems many are concerned with how the space is managed, but few can agree on how 
this piece of land should look. Oak Savanna's require unique management that is complicated by which plants one is attempting to cultivate in the ecosystem. Discussing ecosystem management and site maintenance helps explicate the divided perspectives on the land and how to interact with it from different stakeholder groups. Currently, there is no established management system for the Oak Savanna, and management efforts are collaborative between different concerned parties. The INS community has requested specific forms of ecological engagement from the landscape crew at PSU, such as the request that the native grasses are left undisturbed. The SSC has supported the INS community at PSU in maintaining that standard, however, without an established regimen, users may feel confused or conflicted above the "wild" nature of the site.

Dog owners reported with greatest reliability discontent for how the savanna is currently being managed, expressing that it looked messy, unkept, or half-finished. For dog owners, this challenged their idea of what an Oak Savanna was or how "good" nature is "supposed to" look; one dog owner expressed this by calling into question the name of the area, stating, "...to call it a savanna, that's a stretch.” Dog owners seemed to express some sort of peripheral understanding as to why some have requested the Savanna is not maintained by regularly mowing the lawn or keeping the biodiversity at bay. Brief explanations such as "I know they're working on it but..." demonstrated that dog owners are aware of larger management process and their origins, but that they did not have an in depth understanding of what those preferences implicated. Many expressed that other dog owners might have more respect for the land if it was managed in a way that they would prefer. However, it was obvious these individuals were completely unaware of how their preferences intersected what was for other stakeholder cultural or even spiritual interests when made these requests in passing. 
For this reason, the INS community at PSU has been left with the burden of providing interpretive labor for land stewardship practices in perpetuity. "A lot of the push back that we were doing was education... they just didn't have the full knowledge to take care of it correctly," one INS student leader commented. Not only have they had to remind the maintenance crew not to accidently mow down or remove culturally important plants, they have had to advocate for their protection from potential disruption by curious and oblivious canines. Unfortunately, since the dog owners are equally unaware, they must also be taught how to engage with the Oak Savanna in a way that is respectful to the plant community and neighboring stakeholder groups. However, as the Camas ceremonial planting example highlights, there is still much work to be done in this regard. "I think it's kind of a contested space that people who don't know the history of view as a field," one participant from the SSC explained (certainly, high up PSU developers have largely supported their argument). Although there are many tensions about how to properly manage the area, what the area is intended for, and how to cultivate a space that meets those needs, this key knowledge holder believes those tensions are merely a symptom of having not established a mutual respect and mode of engagement for the space among stakeholder groups. They continue, "I think that a lot of the needs of like preservation, greenspace, education, and scared space could overlap...but I think it's more in the name of [establishing an] ecological model and respecting it."

Arguments about how to best manage the space ecologically highlight how conflict and contest function to establish ownership and agency over the Oak Savanna. Stakeholder groups interact with the area in different and sometimes oppositional ways. Contest provides a space for stakeholder to push towards formal recognition, by reclaiming the Oak Savanna in moments of engagement. The heated debates that result from these moments remind on-lookers and 
stakeholders alike that the Oak Savanna does not have an established caretaker, so much as competing pedagogies and converging systems. Even the PSU planners concede that there is little established precedent for who to call when something is wrong at the Oak Savanna. One of the planners elaborates, “There isn't actually anyone that manages it in a formal way which is part of the issue. It's maintained by campus ground crew. And then also informally by some student groups...The open space itself is not really controlled by any one individual."

As illustrated by exploring the ecological management of the site, certain stakeholder groups assert their ability to manage, and further govern, the land by advocating for certain routine practices at the Oak Savanna. In this way, "control” over the area is collaborative, and constantly being renegotiated between different stakeholder parties. Stakeholder groups police the behavior of one another through both formal and informal means. If you recall the example given earlier about the temporary fence that was put in to protect the plants from disruption, a clearer picture may begin to emerge. Management and "design" of the area is one way to remind fellow stakeholder groups of their boundaries and re-assert personal relationships and investments, or one's vision of the perfect space. I found that this kind of community regulation was actually quite common, regardless of how often stakeholders acknowledged it.

Fencing is just one example of how impromptu design elements become very political means of regulating the behaviors of other stakeholder groups. One participant, a student leader from the SSC, offered a short story about a time the SSC removed an art installation put in by a community member, because they had not asked the INS community or the SSC. Many participants reported that they are often motivated to visit the Oak Savanna to check to see if it has changed since the last time they were there. These kinds of anecdotal narratives describe a web of stakeholders each invested in how they believe the Oak Savanna should look and 
function and actively policing one another's ability to interact with the site in complex and nuanced ways. This act of mutual policing is not just expressed at the ground level, stakeholder groups continue to police one another up the chain. It was reported that facilities may sometimes experience tension with the PSU planners over who ultimately gets to make the decision about Oak Savanna concerns. During my fieldwork, four different individuals, mostly from different offices and sectors of the University, mentioned receiving phone calls from PSU/community members requesting to rent the space for an event or ask a question. This further demonstrates how the government of the area, both the physical space and social idea what the Oak Savanna is, who is it for, and how it should be, is fluid.

As displayed with the example the INS student gave about their experience trying to get PSU to agree to moving the plastic bag station, the idea that there is no centralized power over the area may not be true on all fronts. In this example, the community could not implement a design element simply because they were not granted the authority. Thus, the idea that the Savanna has a flat hierarchy, dependent on self and reciprocal, community "policing," may only be true to the "on the ground" level. However, as I have acknowledged with the example of ecological management, "upward" policing within the bureaucratic system at PSU is sometimes effective, depending on how much recognition you have already been granted.

The physical maintenance and design elements of the space are not neutral, technical elements guiding user relationships, they are active political agents co-producing the reality of the Oak Savanna. This creates a highly complex situation, considering, again, that this is not in discussion a designed thing, it is in discussion with a living savanna, filled with life, love, and memories. Relationships with the Oak Savanna reflect intimate personal realities that may be deeply connected to identity or agency. These then get highly politicized in the context of power 
relationships between stakeholder groups. Because the tensions that arise between stakeholder groups are so political, potentially emotionally taxing, and seemingly indefinitely ongoing, many interview participants expressed a growing apathy toward their own environmental imaginaries. No one has attempted to purposely cultivate Camas at the Oak Savanna in a while. The SSC representatives reported feeling overwhelmed and exhausted by a project they cannot seem to gain control of. The installment of the construction equipment may have deterred some users from returning. Some who had intimate connections to the space may have found it less painful to simply look away from all of the conflict that has resulted over the changing and intersectional identity of this piece of land. This condition leaves the connections between stakeholder groups largely undeveloped in many ways, and most are not aware of the experiences and relationship other stakeholder groups share with the Oak Savanna. I will now examine how participants reported the co-design process addressed these issues and generated interest and empowerment for stakeholder groups.

\section{The Shared Imagination: Deconstructing Collaborative Urban Design}

In this section, I analyze the methodological approaches employed in the co-design meetings, as well as the factors motivating their organization. I discuss how ecological management of the space indicates agency and how competing ideas for how to manage the Oak Savanna are directly political. Qualitative data shows that stakeholders may have had a difficult time communicating both with one another and co-design facilitators throughout multiple dimensions of the process, which I argue led to epistemic gaps. Preconceived notions of certain actors as exhibiting 'active' or 'passive' modes of engagement with the Oak Savanna may interfere with the co-design process by circumventing the synchronization of the varying design epistemologies (Perkins 1986) stakeholders bring into the room. Ultimately, I will make a case 
for how design may unintentionally interrupt the negotiation of design epistemologies between stakeholders, and how this impacted the co-design process of the urban Oak Savanna at PSU.

\section{Evaluating Motivating Factors and Methods}

Tensions are, of course, awkward and perhaps distressing. However, there are clearly many reasons one may want to get all of the different stakeholder groups in a room together to discuss the condition of the Oak Savanna. Historical connections and conflicts among users and the miscommunications that have resulted from them highlight the need for collaboration between stakeholders. It may be that the tensions between stakeholder groups at the Oak Savanna acted as focusing events that inspired the co-design process. When I asked the INS student leader why they believed the co-design meetings happened, particularly at the time that they did, they responded:

When [the INS community] came in, it disrupted the dogs and the students who were using it in that regard...through community action and the ripples that one action has, people became more aware of the site.

One of the PSU planners also explained how these historical conflicts over the proper uses of the Oak Savanna inspired the co-design meetings:

[The Oak Savanna] could be better utilized for sure. That's part of the reason we did the design work around it- to try to imagine what could be... I don't know exactly what the best break down of those uses are...that's part of why we did the study.

Another planner who facilitated the co-design meetings confirmed this analysis by explaining the process in very similar terms, primarily focusing on the power of imagination in these contexts, since they were not going to result in direct policy action. Planners also cited understanding what the current uses of the space are, imagining how the space could be re-designed to encourage and facilitate certain uses, and addressing the tensions that pre-existed in the space as motivating factors for the co-design meetings. 
PSU planners who are working on the long term Open Space Plan for PSU's campus have taken a liking to the Oak Savanna, as it clearly coincides with their values and agendas. The Oak Savanna is located in the heart of PSU, is already "open space" (although it is certainly not empty) and has clearly generated some buzz. During the interview process, the PSU planners explained that to fully assimilate the Oak Savanna into the PSU open space plan, they needed the support of on-the-ground stakeholder groups. Here, one co-design planner and facilitator elaborates:

It's motivated by a desire to keep it as open space. [Some planners at PSU] are real advocates for keeping it as open space in perpetuity. In order to do that, we need to build a coalition, essentially, of people who support doing that and make it seem exciting.

To the planners, the co-design meetings are not merely a process of deciding how needs are met and uses are suggested through collaborative design practices, they are also processes of establishing and accumulating social capital to gain support and recognition within larger community contexts. At the same time, planners emphasize that they are going to help people "begin to see the full potential for [the Oak Savanna]"... indicating that, in addition to creating alliances with existing stakeholder groups who are already very invested and recognize the potential of the Oak Savanna, the co-design meetings are speaking to an audience that does not already have established relationships with the area.

When Oak Savanna user participants were asked, they credited the co-design meetings to a range of things. Numerous reasons were cited as to why the area was potentially being expanded, re-designed, and uses re-negotiated. Some believed the meetings responded to a perceived increasing occupancy of the space, others believed in was to provide greater meaning unto the area, and some stakeholders believed it was in response to their individual or collective group action. 
Planners designed and facilitated the three co-design meetings as part of a larger process of events related to the Oak Savanna and the PSU Open Space Plan. This study is examining how those meetings reflected the interests of different stakeholder groups, according to the individual stakeholders who participated in this study. A great number of participants in this study attended those meetings, but many that I spoke with reported that they not only did not attend, but that they were entirely unaware of the co-design process whatsoever. Of the six formal interview participants that I communicated with, three attended the meetings and three did not. The three individuals who did and not attend the meetings all identified as dog owners, or students who associated with the dog-owning community at PSU. These participants reported that they did not attend because they were never made aware of the meetings or did not receive the information for when and where they were meeting. Of the $30+$ individuals who participated in the study via participant observation, most who attended the co-design meetings identified as members of the INS community or members of the SSC. Participant observation with dog owning groups at the Oak Savanna also found that most of these individuals did not attend because they were not made aware. An actual list of constituents at the meetings was collected by the designers, but that information was not disclosed. Two of the participants who chose to agree to formal interviews were involved in more long-term decision-making processes outside of these three meetings.

The meetings elicited a good number of attendees, and multiple participants told me that the rooms the meetings were hosted in were too small on a couple of occasions. Because of the different dates, there were a differing and a variable number of attendants at each meeting. The meetings were sequential, and each meeting asked participants to consider several distinct aspects of the site. For example, one meeting was entirely dedicated to the selection of plants 
they would like to see cultivated in the space, according to one participant. One student participant who attended all three recalls the general methods employed during these meetings:

...they maybe showed us some potential designs and then we broke into groups and talked about different needs and...visioning for different levels of the ideal space... and there was some more open discussions among the entire group.

It is likely that many more small group activities and thought experiments were used in the meetings than were recorded during my research. Understandably, it was difficult for participants in this study to recount each detail of three meetings that happened on separate days. One of the PSU planners and group facilitators reports that they primarily used what I have called "prototype images" portraying re-imagined versions of the Oak Savanna to elicit feedback on various suggests through illustration. Prototype images are computerized models of the Oak Savanna, generated by the contracted landscape design company, which feature the space reconfigured with new and interesting features and activities (see Figure 2). One of the planners explained that these images would be shown, and their features briefly interpreted before the designers asked for feedback on them from co-design participants. The feedback was collected by having individuals raise hands, facilitating independent small group discussions, and written response forms.

After the first two co-design meetings, the design company used the information they had collected to produce three additional prototype images, each informed by the feedback they solicited previously. At the third meeting, they presented these three images, and asked participants to express things they liked and did not like about each. This concluded the series of three meetings. After all three meetings had been completed, one final prototype was generated as the resulting product of these co-design meetings. A series of five images (all different angles of the same imagined, prototype space, informed by the series of co-design meetings) were 
published on the webpage of the design company as an example of their work. Three participants that I showed these images to referred to them an amalgamation of three prototypes presented at the third meeting. Participants in this study who attended the co-design meetings also reported that the designers told them that these 'final' prototype images (final only in the sense that they are the product of the three finished co-design meetings) would be distributed back to participants via e-mail, but were never sent out. "I feel like the designs were supposed to be shared a lot more widely," one participant commented, "They definitely said they would share the information with everyone that went, and I don't think they necessarily did." The designers may have chosen not to share them due to the fact that these images did not necessarily result in the expansion or re-design of the Oak Savanna. However, as I have explained previously, these images are emblematic of the co-design process, and represent the feedback as it was heard and interpreted by the facilitating designer and planners. Many expressed dissatisfaction at the idea that they had not seen these images until I presented them to them.

Underlying differences in the fundamental understanding and recognition of the space carried into the communicative dimensions of the co-design meetings. Although most participants reported that they did not feel any direct barriers to expressing their input and opinions, some found it difficult to get past the different social and cultural interpretations of the space. One INS student explains what is was like for them expressing their concerns to other stakeholder groups at the meeting:

...it was a little strange. Kind of like... [we] were talking about the same piece of land...but it was just like a difference in the way that we were talking that made it, not uncomfortable, but just like a little weird. Kind of like when you start reading Shakespeare [and] it takes like two days for that language to stick? It was along those lines. Like, I understand what you're saying but it's just said in a slightly different way. I guess a little bit of cognitive dissonance happening. 
While recounting the meetings, this participant recalls that it was difficult to collaborate with other stakeholder groups who did not understand the space in the same way that they did. This likely is related to the historical relationship the INS community carries with the Oak Savanna, and more largely the bioregion in which the study takes place. The participant uses phrases such as "cognitive dissonance" to express the degree to which stakeholder perspectives may have talked past one another. Cultural recognition of the land as living, breathing, sacred, and potentially even an ancestral (depending on the individual) may have caused INS community participants to register other suggestions made as more than disjointed from their own epistemology. It appears that some suggestions, made both from other stakeholders and facilitators, may have registered as inappropriate or offensive. Another student from the INS community who attended the meetings provides an example of a suggestion from the facilitators that indicted to them a communicative gap or incohesive social understandings about the savanna:

I think part of the tension [in the meetings] was one of the things they brought up, which only one person reacted positively to, was something about a.....(laughs) basketball courts or something like that. So, I think they did throw in some things that felt...like, I understand from a planning perspective why they would include them, but also I think that they offended some of the people in the room and didn't really serve the purpose they were hoping to.

During participant observation, another group of INS students explained how one of the activities they were asked to participant in during the co-design meetings made them feel like they were assimilating away from their own ideas about the space. In this exercise, participants reported that they were asked to divide into small groups and were given a large image of the space for them to lay out in front of them. They were then provided stickers that depicted different activities or physical structures and asked to place them around the image of the Oak Savanna. Because the designers have chosen not to participate in this study, I cannot know why 
this exercise was chosen for the co-design meetings. However, I assume it provided the designers data on how users wanted to see activities and structures dispersed across the space, among other things. Participants explained that one set of stickers they were given to strewn across their Oak Savanna reproduction contained images of sports equipment and an industrial stake park. I watched as participants conveyed that some were offended by the suggestion that these images were appropriate for the space through awkward recollections of the process. Some relayed that they did not participate in this activity whatsoever after seeing these images, politely leaving them on the side of their Oak Savanna reproduction, keeping it unmarked.

These examples demonstrate how the different paradigms for engaging the space each stakeholder group brought into the co-design meetings created communicative divisions among collaborators, primarily the INS community, who have an emphasized and very special relationship to place. Some have expressed that the disjuncture experienced during these meetings may have increased existing tensions or highlighted misunderstandings while stakeholders were together. However, many formal interview participants were empathic with the design and planning team who facilitated these meetings and would even offer explanations for their behavior such as, "they did want people to think from each other's perspectives," or, "It's important to have all the voices heard." Others were less understanding and felt as though their pedagogical or design approach was simply being dismissed during collaborative design sessions. This kind of interpretive labor, where participants attempt to justify and contextualize the processes that are being asked to preform, may indicate that they simply feel uncomfortable or unwilling to ask why these processes are happening the way they are. Instead, they create personal reasons for why they have been asked to do certain things and project them onto the facilitators, regardless of their accuracy. 
Additionally, it is worth noting that some did feel there were some barriers to expressing their feedback to the designers. One participant explained it did not seem as though their feedback was genuinely valued, and that they were hurried along:

I don't know if they had a bad day, they could have. But it was very obvious that they were kind of along the lines of, 'Okay, just hurry up. We wanna scatdaddle.' Which I'm sure they were under a deadline as well, but I guess just the way the facilitator that day held himself was not very welcoming. And I don't know if that was just towards me or other people were feeling it that day...

During participant observation, it became apparent that this attitude was shared among a couple members of the INS community. Aside from not knowing when and where the meetings were happening or time constraints, designer-ly attitude was cited as the largest barrier to participating in the co-design meetings. Most participants did feel that they were encouraged to share their perspective, and it seems that the way that input was received by designers varied according to participants in this study.

Active and Passive Uses: Imagining the Imagination

I now revisit my earlier argument about the Oak Savanna's dual qualities of both serenity and remoteness and an energetic, lively community space. These dual qualities appear to become separated and associated with distinct users by essentializing the behaviors of stakeholder groups. Stakeholders become essentialized in the sense that the may be perceived as one dimensional, engaging in only certain practices that 'fit' that stakeholder community, when in reality, I argue their modes of engagement are much more complex. By imagining the stakeholder's behaviors and attitudes in this way, it seems that certain types of users are attracted to the more "active" uses (i.e. bringing the dog to play, engaging in child, family, or adult recreation, or visiting classrooms) and others are drawn to "passive" uses (i.e. ecological care or restoration, studying, or practicing spirituality). One of the PSU planners explain how they perceived this dichotomy to have played out: 
I think there really was a tension between the number of people who participated in the study who said, 'This should all be set aside as open space for restoration and shouldn't really have any other uses.' Other people were like, 'No, we need to have other active kinds of uses here.'... And since we don't have a lot of open space that we control here on campus, it becomes a very potentially heated discussion about what's right for the space.

In the mind of this planner, there is little overlap between those who want what they refer to as active and passive space. They express that these tendencies are adopted by such distinct groupings that they may even result in conflicts between them. Although they were not at the codesign meetings, dog owners seemed to share concerns regarding potential conflict arising as the result of overlapping active and passive uses in the prototype images. When discussing the walkway portrayed in the images (see Appendix B) though the middle of the space (an addition that is arguably encourage active usage but was perceived by them as an example of passive usage), dog owners responded negatively: “It doesn't make it easy for dogs and like it's not going to change the fact that people are throwing stuff for their dogs. So, it's just going to be more people getting hit." This is a clear example of active and passive uses positioned at odds and being rigidly associated with certain stakeholder groups (in this example, they are essentializing their own usage patterns).

Of course, illustrated with the Camas ceremonial example, uses can and do interrupt uses. But it is how these uses get imagined and ascribed to different stakeholder groups by planners, designers, and facilitators that may overlook some of the complexities of usage and stakeholder needs. A number of examples of how this happens was brought to light by evaluating and reflecting on the co-design process in this study. One student participant explained that some of the suggestions for facilitated lounging in the Oak Savanna interrupted cultural or spiritual uses: "The ideas that introduced more pavement to the space, I could see the visual appeal, but I was a little worried about those and how they would maybe offend some of the INS community by not 
making it feel like a sacred space.” The introduction of pavement is not inherently associated with active or passive use, but for this participant, it indicated disruption of a different kind. In a somewhat indirect way, I believe this participant is speaking to the incongruencies of competing design epistemologies (Perkins, 1986). I argue that this example substantiates that it may be more nuanced than active uses interrupting passive uses or vice versa.

This dynamic of active and passive becomes increasingly complicated by one INS leader's description of both their favorite and least favorite aspect of the final prototype images. This participant explained that their favorite aspect of the final prototype images was the raised walkway proposed to run across and cut directly through the majority of the space (the same walkway I discussed earlier) because it encouraged what the designers would call "passive" usage:

Prairie grass can be fairly fragile, and the habitat and insects can take a bit of time to really build up. So, the fact that they have people walking on this pathway elevated above the ground so that... even the grasses have the ability to go underneath it is really awesome. Probably my favorite thing about it.

By contrast, when asked what their least favorite element of the proposed designs was, they directed their criticism toward the elevated half circle near the center of the savanna, stating it did not seem large enough for what would be considered more active uses:

I feel like putting something [with] that much elevation kind of breaks up the space a little too much and makes it so that...the small groups that go there today, they would have to be even smaller to accommodate the way that it would be designed...

These examples are key for deconstructing the active and passive use dichotomy that is perpetuated in the rhetoric surrounding the Oak Savanna frequently, not just in the co-design meetings, but by stakeholders more broadly. These associations harken back to the dichotomy established by positioning dog owners and the INS community as opposites, when in reality, I argue, they are much more similar than they appear on the surface. 
If one adopts the passive and active dichotomy, it seems as though this participant cannot make up their mind. The structures that encourage active uses (elevated half circle) are not large enough, yet the structures that encourage passive uses (the walkway facilitating the growth of Prairie grasses) are their favorite part of the design. One can also see that it this example, active and passive conceptions of use become complicated by which species we are talking about; the plant people get increased active usage by pacifying the human usage and encouraging passive forms of engagement. However, stakeholders do not adhere to these dichotomies (even if they project them onto other stakeholder groups). They may instead be a product of the popular rhetoric around the savanna that has become adopted by planners and facilitators of the co-design process. These discourses imagine stakeholders and their uses at inherently at odds with one another, and that the conflict generated from that is a natural consequence of sharing space. By projecting popular biases onto the co-design participants and deciding a priori the ways in which they relate to and conceptualize the Oak Savanna and it's uses, planners and stakeholders may have 'imagined the imagination' of the participants in a way that was instructive to the process (Metzger 2013: 783).

One INS student leader cited throughout this study articulated the imaginative disjuncture between themselves and the co-design facilitators by problematizing the walkway, not because it encouraged the sensitive plants to grow, but because it discouraged direct human interaction with plants. They did this by comparing the Oak Savanna to another tribal land they recalled sharing similar feelings about when it was re-designed by the county:

There's this one site of my tribes'. It's where a river starts and it's beautiful. And [the county] went in and they... put in some fountains and they did all of this work. It looks very beautiful and crisp and clean. But it kind of feels like aspects of a museum overlaid on top of traditional land. Which this is what this [prototype image] feels like very much to me... Like I said, I really like this wooden pathway. But maybe the way that they have 
it designed- it just feels more like, 'Walk through the prairie and as you turn to your right you will see an Oak Savanna.'... And I think as an indigenous person I have more sensitivity to that feeling, because that's where most of my, like tribal basketry is held in museums and private collections.

In this example, museums are used to signify passive usage- they encourage one to look, but do not touch. This sense of "showing off" the space, and even the plant people, may have denied human people the opportunity to interact with them in meaningful ways. This greatly complicates what it means to be 'active' vs. 'passive' in this space. Another INS student explains that the prototype images reflect this misconception,

I feel like part of what they're trying to do is appeal to the INS users, and say 'look, we're helping preserve the plants.' Without acknowledging the importance in indigenous cultures of humans interacting with the environment.

Under these frameworks, passive and active uses are not at odds. Further, passive and active may be seen as un-useful categories that disregard the complex nature of interaction between living individuals (human groups and the Oak Savanna) and various design epistemologies. Ultimately, it seems that the different ways people have used and engaged with the Oak Savanna may contrast and coincide in ways that are largely ideological rather than structural or policy driven.

What will this co-design process result in moving forward? Regardless of whether or not it reflects the needs and interests of different stakeholder groups, what has this process worked to established? How has it inspired impacted communities to imagine space, place, and even the minds of one another in ways that address historical conflict? These are all questions that do not have definitive answers and should continue to be explored. However, I argue that participating in these processes is not directly related with establishing a feeling of ownership over the collaboratively designed image, as some participants felt the resulting images did not reflect their relationship to the Oak Savanna. 
During participant observation, one INS student expressed that it felt like the designers were listening to their input, but that the interest they were articulating to the designers came second to the predetermined goals of the larger design process and agenda. They described it terms of percentages, explaining that the designers would listen to their feedback, and then come back to them with a model that was " $30 \%$ what we told them, and $70 \%$ what they wanted to do anyways." "What they wanted to do anyways," primarily referred to an idea the PSU planners emphasized during the co-design meetings, in which they described connecting the Oak Savanna to a nearby food cart pod through the implementation of certain pathways. This INS student reported that the desire to connect the Oak Savanna to the food cart pod, a desire that was conceived and perpetuated by the designers beforehand, may have detracted from the input they provided. The increased agency the designers recognized from the planners (as they are their employers, after all) may have created hegemonic channels through which information was filtered and processed.

Further, these meetings have not yet left stakeholders with new ways to co-manage the Oak Savanna. They may even discourage community collaboration entirely by transferring the ownership over a community driven space into the hands of the PSU administration and planning team. During my time visiting one of the PSU planners, they expressed irritation at this study. They told me that they did not have to allow for public input at all, and that they regularly conducted similar projects without soliciting community feedback. Their frustration was misdirected, but these transactions are of telling of how design practices serve to reinforce power dynamics that may otherwise become slippery during instances of reclamation. After viewing the prototype images, many participants questioned how established uses of the space would adapt to the proposed changes, particularly if the changes did not speak to their needs. 
For a majority of the time, my community has no say in anything that really happens around us. And so, we're always just kind of like, 'Okay, you do what you're going do and then we'll do what we're going do when you're done.'

For many participants, the identity of the land is determined by the users. These assemblages of land, plants, animals, humans, and social realities determine interpretations of space very powerfully. Design can interrupt these negotiations, by reestablishing dominance through practices of land ownership, formalized control, and re-arranging (otherwise known as designing).

\section{Discussion}

During infrastructural design processes, it is common that planners will not consult the public until absolutely necessary (Harvey \& Knox 163-185). Co-design appears to be contrary to this, appreciating the importance of local knowledge at the forefront of the design process. This study illustrates that this notion is greatly complicated by the more long-term design processes cushioning the charette co-design meetings. In this study, processes of design were occurring across greater scales that resulted from design expertise and epistemologies already adopted by the planners and designers in charge. Thus, as one of the planners illustrated by attributing the co-design process to amassing support for development goals already established, co-design may fall into similar patterns anthropologists have noted previously about why designers involve the public in their projects. These reasons include, but may not center, public interests, so much as public support.

Further, former evaluations of co-design by urban planners highlight the agonistic potential of having different stakeholder groups co-design space through active participation in the physical co-construction of space (Munthe-Kaas 2015). However, as the historical feud the INS community members have sustained with dog owners shows, agonism is the product of 
more than just using one space for multiple purposes at the same time. At the Oak Savanna, stakeholders have trialed this method naturally, not being prompted by designers, dropping by the space whenever they see fit. This study has shown that it is, instead, more useful for researchers to closely follow the "protocols of co-design" (Palmas \& von Busch 2015: 246) when examining the incredibly specific conditions under which agonism and creative productivity are inspired. These seemingly utopian modes of collaboration are not a natural product of people sharing space and learning the "right way" to co-habit. As this study exemplifies, co-design does not, in and of itself, eliminate historically encountered feuds as a natural product of co-design process, and participants of this co-design process are still arguing about disrupted plants and dog poop to this day.

This study clarifies how imposed structures of power that the co-design processes intends to alter by granting agency to stakeholders through engagement, do not necessarily unsettle power dynamics that exist outside of these spaces. Rather, some planners expressed that participants should feel grateful to be given a means to exercise their voice whatsoever. This attitude may erase the ways stakeholder have been making their opinions heard all alongthrough subtle methods of design negotiations (such as fences, ceremonies, and dog poop) that are not formally recognized by design expertise. Participants also reported that their input was only assimilated so far as it was understood and already fit into the planning universe of the facilitators. Epistemic gaps meant that design suggestions were often misinterpreted, as the INS participant's comment about the "museum-izing" of the Oak Savanna indicates. And these miscommunications, which highlight the power inequalities in the room, reveal that it is indeed the invisible mechanisms of co-design, such as pedagogy and engagement, that either support or confound platforms for community learning (Palmas \& von Busch 2015: 246). 
The invisible mechanisms at play, in this case, include histories, stories, and relationships to place that the designers could not fully account for, which may have very well been due to time and fiscal constraints. It is the relationships to the space that are being re-negotiated, rather than the agency of participants, and these invisible pieces of the assemblage are that which "fill in the gaps" between visible human processes of design (Murphy 2016: 443). Thus, it is not just the human actors that "hold together" infrastructural design projects between them (Harvey \& Knox 2015: 6) but also the epistemic and critical roots that precede them. These "forms of micropower," as Palmas \& von Busch refer to them (2015: 246), are deeper than overt acknowledgments of certain actors as having more influence over the design process or having "better" epistemologies. I instead am arguing that in this case, epistemologies were flattened by most if not all actors through the co-design process, reducing stakeholder patterns of engagement in ways that are productive for designing form (such as the establishment of active and passive uses), but not for acknowledging complex social processes. I do not wish to simplify the divisions of epistemic viewpoints between stakeholders, as there is, of course, a certain hybridity to all ways of knowing (Gupta 1998). Rather, I argue that is it the incredibly nebulous, interwoven, and murky qualities of knowledge that create this hybridity, and thus deserve further attention by designers.

Designer's use prototypes to gain "critical distance from the present," in which they can hypothesize potential directions for social action or thought through provocative images of what could be (Hunt 2010: 39). This may be true, but this study indicates that those future oriented framings are not inherently critical in and of themselves. Rather, the Oak Savanna co-design prototype images may not represent the interests of co-design participants not merely because they have competing interests (which I argue are not so competing at all), but precisely because 
they gain too much distance from the present without critically engaging what is already there. This indicates that designers may be designing people through imagining place, rather than designing place through imagining the interests of people (Buchli 2013). By "prototyping the social" (Hunt 2010: 33) and mapping stakeholder interests onto the prototype images in ways that are one-dimensional (conceptualized in this study by active and passage uses), designers may have essentialized understanding of stakeholder's behaviors, attitudes, modes of engagement, and design epistemologies.

Thus, if we are to learn something from the co-design of the Oak Savanna that can be applied to the disciple of design and urban planning, it is about stakeholder engagement. Design leads with suggestions that are "audacious with respect to intervention" (Murphy 2016: 443), which places significant influence on their subjective affiliations outside the arena of co-design (seen in this study through the suggestion of things like stake parks and food cart pods). This case study supports the idea that design is thus limited in its methodological approach by not remaining critical of its own social locality (Suchman 2011: 16). But designers are not ethnographers who can simply adapt our approaches, they are subject to sets of constraints ethnography often does not allow for (Bichard \& Gheerawo 2011:46). Bichard \& Gheerawo (2011) argue that "Conducting research with people allows [designers] to reflexively search for points of inspiration rather than seeking social truths." I argue that this case study illustrates how this is not always true. Indeed, designers may come upon social truths by limiting their explorations of stakeholder identities (as active or passive) at the fore front of the design process (referred to by these authors as a kind of "rapid ethnography"), done through their invocation and articulation of stakeholder groups (Metzger 2013: 783). In searching for that inspiration, 
designers and planners may come open and inherent these social truths by not intentionally using critical modes of engagement with the public.

\section{Conclusion: Towards an Ethnographically Informed Design Praxis}

This study used a political ecology framework to uncover the politics of design as they apply to formations, and re-formations of the natural world. The urban Oak Savanna is a unique site in size, origin, and management practices, but it is a microcosm of conflicts that occur all over the city of Portland and the larger urbanized world. This study is not only important and informative to this specific moment in PSU's development, but also informative for models of collaborative, urban land development in the Pacific Northwest. Stakeholders retain complex and sometimes seemingly oppositional relationships to place, which is expressed through interaction and manipulation with the environment as one see's fit. At the Oak Savanna, these conflicts have been addressed through co-design meetings and activities, that are symbolic tools of collaboration, implementation, and power. Ethnographic interviews and other qualitative methods have shown that stakeholders have perplexing associations of the space as both peaceful, serene and lively, engaged spaces. Although these two associations exist simultaneously in the minds of stakeholders, the designers who have analyzed these relationships have grafted only certain sections of those realities onto each group, primarily determined by whether they are favoring "active" or "passive" uses. But this dichotomy cannot account for the design epistemologies that are brought into co-design meetings, which, I argue, are much more complex than "touch or do not touch". They reflect cultural, spiritual, and personalized histories that understand place in different ways, as well as socio-ideological-material associations.

However, designers conceptualize stakeholder conflict as the result of users wanting to use the space in different ways, rather than having different embodied understandings of how to 
interact with, and develop a relationship with, place. For the dog owners, interacting with place is more so about conceptual social motifs such as community, relaxation, or space for usage, while for INS community members, engaging with Oak Savanna meant careful attention to technical aspects of the space, reciprocal teaching and learning from plants and the landscape, and using spatial awareness to facilitate themes of education, generational learning, love, and traditional ecological knowledge. Tensions between them may both be inevitable and useful, in certain aspects. But what is more crucial, and what I wish to argue here, is that tensions have created well codified stakeholder groups who are often at odds with one another over accessing their needs, interests, and spatial associations. Moments of conflict reinforce to the various stakeholder groups that they are in fact, very different, which only reproduces ideas about competitive engagement with the Oak Savanna between them. Co-design is complicated by this "competition" between design epistemologies (Perkins, 1986) that are brought into the process, including (and most importantly) those of the designers themselves. But I argue that this competition is, more than anything, ideological, and heavily influenced by the ways stakeholders are epistemologically evoked at the forefront of the co-design process (Metzger 2011). Analysis of these practices has shown that designers reinterpret what is shared with them by stakeholders in ways that do not consider their own biases about them, or those which they project onto one another (Suchman 2011). Because the proper governance of the space is contested, designers also use co-design a mechanism to re-assert their ability to disrupt public negotiations of space. This is not in and of itself problematic, but it does mean that ecological design is a very powerful tool for determining both social (and perhaps ecological) futures (Hunt 2010), even if actual land is never given a new form. I do not argue that this is a negative quality of co-design, but rather a lofty responsibility of the co-designer. 
This research has also shown that uncertainty can be invoked by designers to placate codesign participants who feel uncomfortable with the suggestions being made by designers through prototype, and that this may spur apathy in stakeholders who lose faith in their influence over the process. In the future, designers could clearly outline the parameters of their studies or design methods to ensure participants are aware beforehand of what they are being asked to do. This will also make it easier for designers and city planners to hold themselves accountable by returning the research in ways that are appropriate and outlined in the beginning of the study. Co-design, in the form that has been analyzed here, is primarily a social and ideological phenomenon, and should be approached as such, exploring issues such as environmental imaginaries, cultural affinities, and social relationships around place rather than technical placement of infrastructural objects and activities.

If co-design is truly intended to ensure everyone has a seat at the table, then as academics we must require ourselves to do the work involved with verifying the accessibility and impact of these spaces and processes (Palmas \& von Busch 2015). My desire is for this study to offer the university feedback on the process of co-design they have employed and provide designated, uninterrupted spaces for co-design participants to express their relationship to the creation process and the developing downtown environment as a whole. In this way, the study is also significant because it speaks to larger community processes of invention, innovation, and influence in the Portland metro area. Diverse groups hold interests in these important places because they are public resources that are supposed to be available to wide audiences (Dunham, 2017; Dunnett et. al. 2002). It is critical that studies such as the one proposed here continue to contribute to our understanding of how urban green areas are created, managed, and restored to serve the common good (Weng 2011). 
Thus, this study has highlighted the role of anthropology in continuing to contribute to design practices, especially as they apply to the natural world. Anthropology's extensive history of reflecting on how the dominate frameworks employed by the discipline allowed researchers to conceptualize the other (largely influenced by feminist thought) have led anthropology to careful examinations of difference and likeness between researchers and those with whom they collaborate with and work for (Haraway 1988: 589, Clifford 1986, Mascia-Lees et. al. 1989). It has also led to careful examinations of difference and likeness between different cultural units, or what's conceptualized here as stakeholder groups (Stolcke 1995, Boellstroff 2003). Designers should continue to engage ethnographic theory and question how their own personal and professional understandings and motives blur their ability to critically engage both themselves and those with whom they work. Designers and city planners benefit from explicitly asking who profits from their proposed and realized visions and recognizing that direct interactions with stakeholders through methods like those of co-design may still face many obstacles that anthropology has explored for decades. This absolutely does not mean that co-design is inefficient or should be abandon by designers and city planners. On the contrary, it is the closest way to come to challenge the assumptions designers have about those for whom they design. However, co-design, like all methods that engage public knowledge holders and key figures (be them ethnographic or not) require up front evaluations of the social locations of facilitators, and limitations of certain methodological practices (Suchman 2011). This practice must take on new and novel dimensions, as designers and planners are not trained nor expected to perform like anthropologists. Thus, it remains to be explored how designers can adopt the lessons learned by anthropologists and use reflexive practice to facilitate projects that involve the other. If designers can do so successfully, they will avoid having to take the painstaking route anthropologists have 
shadowed as they learned these lessons at the expense of the populations with which they worked and were hoping to understand and represent. 


\section{Notes}

1- The example I am describing here is from a specific narrative shared with me by a young woman who regularly visits the Savanna. She explained to me that she recently began babysitting the children of a family she met and spent time with at the Oak Savanna.

2- The Karl Miller Business Center and the Viking Pavilion are developments PSU have erected in last two years from the date of writing this paper. They are often conflated with the Oak Savanna co-design process by participants in this study as aspects of the same development project long-term, even though it is clear that these projects are not related beyond the fact that they all occur at PSU and share boards of decision makers within PSU's bureaucratic system. 


\section{References}

Agrawal, Arun, and Clark C. Gibson. 2001. Communities and the Environment: Ethnicity, Gender, and the State in Community-Based Conservation. New Brunswick, N.J. : Rutgers University Press.

Ahn, Changwoo. 2016. "A Creative Collaboration between the Science of Ecosystem Restoration and Art for Sustainable Stormwater Management on an Urban College Campus." Restoration Ecology 24 (3):291-97. https://doi.org/10.1111/rec.12341.

Baker, Mark, Stephen Hincks, and Graeme Sherriff. 2010. "Getting Involved in Plan Making: Participation and Stakeholder Involvement in Local and Regional Spatial Strategies in England." Environment and Planning C: Government and Policy 28 (4): 574-594.

Bernard, Russel. 2002. Research Methods in Anthropology: Qualitative and Quantitative Approaches. 3rd ed. Altamira Press.

Bernard, Russel, and Gery Ryan. 1998. “Text Analysis: Qualitative and Quantitative Methods.” In Handbook of Methods in Cultural Anthropology, 595-646. Altamira Press.

Bichard, Jo-anne, and Rama Gheerawo. 2011. "The Designer as Ethnographer: Practical Projects from Industry.” In Design Anthropology, 45-55. SpringerWienNewYork.

Boellstorff, Tom. 2003. "Dubbing Culture: Indonesian Gay and Lesbi Subjectivities and Ethnography in an Already Globalized World.” American Ethnologist 30 (2): 225-42.

https://doi.org/10.1525/ae.2003.30.2.225.

Bourdieu, Pierre. 1970. “The Berber House or the World Reversed.” Social Science Information 9 (2): 151-170. https://doi.org/10.1177/053901847000900213.

Buchli, Victor. 2013. An Anthropology of Architecture. London; New York: Bloomsbury.

Clifford, James. 1986. "Partial Truths." In Writing Culture: The Poetics and Politics of Ethnography, 1st ed. Berkeley: University of California Press.

Collier, Marcus J., Zorica Nedović-Budić, Jeroen Aerts, Stuart Connop, Dermot Foley, Karen Foley, Darryl Newport, Siobhán McQuaid, Aleksander Slaev, and Peter Verburg. 2013. "Transitioning to Resilience and Sustainability in Urban Communities." Cities, Current Research on Cities, 32 (July): S21-28. https://doi.org/10.1016/j.cities.2013.03.010.

Crowe, Philip R., Karen Foley, and Marcus J. Collier. 2016. “Operationalizing Urban Resilience through a Framework for Adaptive Co-Management and Design: Five Experiments in Urban Planning Practice and Policy.” Environmental Science \& Policy 62 (August):112-19. https://doi.org/10.1016/j.envsci.2016.04.007.

Dunham, Haley. 2017. "Oak Savanna Needs Assessment.” 
Dunnett, Nigel, Carys Swanwick, and Helen Woolley. 2002. "Improving Urban Parks, Play Areas and Green Spaces.” Department for Transport, Local Government and the Regions. http://publiekeruimte.info/Data/Documents/e842aqrm/53/Improving-Urban-Parks.pdf.

Dzhambov, Angel, and Donka Dimitrova. 2014. “Urban Green Spaces’ Effectiveness as a Psychological Buffer for the Negative Health Impact of Noise Pollution: A Systematic Review." Noise and Health 16 (70):157. https://doi.org/10.4103/1463-1741.134916.

Escobar, Arturo. 1999. "After Nature: Steps to an Antiessentialist Political Ecology.” Current Anthropology 40 (1):1-30. https://doi.org/10.1086/515799.

Escobar, Arturo. 1996. "Construction Nature: Elements for a Post-Structuralist Political Ecology." Futures 28 (4):325-43. https://doi.org/10.1016/0016-3287(96)00011-0.

Gatt, C., and T. Ingold. 2013. "From Description to Correspondence: Anthropology in Real Time." In Design Anthropology: Theory and Practice. New York: Bloomsbury.

Gilbert, Scott F., Jan Sapp, and Alfred I. Tauber. 2012. "A Symbiotic View of Life: We Have Never Been Individuals.” The Quarterly Review of Biology 87 (4): 325-41. https://doi.org/10.1086/668166.

Gunn, Wendy, and Jared Donovan eds. 2012. Design and Anthropology. 1 edition. Burlington, VT: Routledge.

Gupta, Akhil. 1998. Postcolonial Developments: Agriculture in the Making of Modern India. Durham: Duke University Press.

Graffam G. 2010. “Design anthropology meets marketing.” Anthropologica 52(1):155-64

Grahn, Patrik, and Ulrika K. Stigsdotter. 2010. "The Relation between Perceived Sensory Dimensions of Urban Green Space and Stress Restoration." Landscape and Urban Planning 94 (3):264-75. https://doi.org/10.1016/j.landurbplan.2009.10.012.

Haraway, Donna. 1988. "Situated Knowledges: The Science Question in Feminism and the Privilege of Partial Perspective.” Feminist Studies 14 (3): 575-99. https://doi.org/10.2307/3178066.

Harding, Sandra G. 1986. The Science Question in Feminism. Cornell University Press.

Harvey, Penny, and Hannah Knox. 2015. Roads: An Anthropology of Infrastructure and Expertise. Ithaca, US: Cornell University Press.

Hassan, Gerry, Melissa Mean, and Charlie Tims. 2007. The Dreaming City.

Healey, P. 1998. "Building Institutional Capacity through Collaborative Approaches to Urban Planning." Environment and Planning A 30 (9): 1531-1546. 
Hunt, J. 2010. "Prototyping the Social: Temporality and Speculative Futures at the Intersection of Design and Culture." In Design Anthropology: Object Culture in the 21st Century, 33-44. New York: Springer.

IDEO.org. 2015. The Field Guide to Human-Centered Design. 1st ed. San Francisco.

Jørgensen, Ulrik, Hanne Lindegaard, and Tanja Rosenqvist. 2011. "Engaging Actors in Co-Designing Heterogeneous Innovations." In Proceedings of the 18th International Conference on Engineering Design (ICED 11): Impacting Society through Engineering Design, 453-464.

Khandkar. 2009. "Open Coding.” http://pages.cpsc.ucalgary.ca/ saul/wiki/uploads/CPSC681/opencoding.pdf, Accessed June 2018.

Kimmerer, Robin Wall. 2013. "The Gift of Strawberries." In Braiding Sweetgrass: Indigenous Wisdom, Scientific Knowledge and the Teachings of Plants, 22-32. Milkweed Editions.

Latour, Bruno. 1985. "Give Me a Laboratory and I Will Raise the World." In Science Observed. Perspectives on the Social Study of Science, 141-171. London: SAGE Publications.

Latour, Bruno. 2007. Reassembling the Social: An Introduction to Actor-Network-Theory. OUP Oxford.

Larsen, Henry, and Claus Have. 2012. "Emergence of User Identity in Social Interaction.” In Design and Anthropology. Farnham, Surrey; Burlington, VT: Routledge.

Legacy, Crystal. 2010. "Investigating the Knowledge Interface between Stakeholder Engagement and Plan-Making." Environment and Planning A: Economy and Space 42 (11): 2705-2720. https://doi.org/10.1068/a43164.

Marres, N. 2005. "No Issue, No Public: Democratic Deficits after the Displacement of Politics." Doctoral Thesis, Amsterdam: University of Amsterdam.

Mascia-Lees, Frances, Patricia Sharpe, and Colleen Cohen. 1989. "The Postmodernist Turn in Anthropology: Cautions from a Feminist Perspective." Journal of Women in Culture and Society 15 (1): 7-33.

Milestone, Juris. 2007. "Design as Power: Paul Virilio and the Governmentality of Design Expertise." Culture, Theory and Critique 48 (2): 175-198.

Metzger, Jonathan. 2013. "Placing the Stakes: The Enactment of Territorial Stakeholders in Planning Processes." Environment and Planning A: Economy and Space 45 (4): 781-796. https://doi.org/10.1068/a45116.

Morgan, Lewis Henry. 1965. "Houses and House-Life of the American Aborigines." In Classics in Anthropology. Chicago: University of Chicago Press. 
Mouffe, Chantal. 2007. “Artistic Activism and Agonistic Spaces.” Art \& Research 1 (2).

Munthe-Kaas, Peter. 2015. "Agonism and Co-Design of Urban Spaces." Urban Research \& Practice 8 (2): 218-237. https://doi.org/10.1080/17535069.2015.1050207.

Murphy, Keith M. 2013 “A Cultural Geometry: Designing Political Things in Sweden.” American Ethnologist 40 (1): 118-131. https://doi.org/10.1111/amet.12009.

Murphy, Keith M. 2016. "Design and Anthropology.” Annual Review of Anthropology 45 (1): 43349. https://doi.org/10.1146/annurev-anthro-102215-100224.

Naples, Nancy, and Barbara Gurr. 2014. "Feminist Empiricism and Standpoint Theory: Approaches to Understanding the Social World." In Feminist Research Practice, 14-41. Los Angeles: SAGE Publications.

Perkins, David N. 1986. Knowledge as Design. Hillsdale, N.J.: L. Erlbaum Associates.

Pirinen, Antti. 2016. "The Barriers and Enablers of Co-Design for Services." International Journal of Design; Taipei 10 (3): 27-42.

Portland State University, n.d. "Portland State Sustainability | Open Space Plan." Accessed April 8, 2018. https://www.pdx.edu/sustainability/open-space-plan.

Portland State University. 2016. "Campus Growth Over Time Animation.” Accessed April 8, 2018. https://www.pdx.edu/sustainability/sites/www.pdx.edu.sustainability/files/Campus\%20Growth\% 200ver\%20Time\%20Animation\%20Update_July_2016.gif.

Rapoport, Amos. 1969. House Form and Culture. Foundations of Cultural Geography Series. Englewood Cliffs, N.J.: Prentice-Hall.

Rosaldo, Renato. 1993. Culture \& Truth: The Remaking of Social Analysis. Boston: Beacon Press.

Schensul, Jean, and Maragaret LeCompte. 2013. Essential Ethnographic Methods: A Mixed Methods Approach. Lanaham: Altamira Press.

Squires S., B. Byrne, eds. 2002. Creating Breakthrough Ideas: The Collaboration of Anthropologists and Designers in the Product Development Industry. Westport, CT: Bergin \& Garvey

Stolcke, Verena. 1995. "Talking Culture: New Boundaries, New Rhetorics of Exclusion in Europe.” Current Anthropology 36 (1): 1-24.

Susskind, Lawrence, and Alan Weinstein. 1981. "Towards a Theory of Environmental Dispute Resolution." Boston College Environmental Affairs Law Review 9 (2).

Suchman, Lucy. 2011. "Anthropological Relocations and the Limits of Design." Annual Review of Anthropology 40 (1): 1-18. https://doi.org/10.1146/annurev.anthro.041608.105640. 
Tuhiwai Smith, Linda. 2013. Decolonizing Methodologies: Research and Indigenous Peoples. London, UK: Zed Books.

Vries, Sjerp de, Robert A. Verheij, Peter P. Groenewegen, and Peter Spreeuwenberg. 2003. "Natural Environments-Healthy Environments? An Exploratory Analysis of the Relationship between Greenspace and Health." Environment and Planning A: Economy and Space 35 (10):1717-1731. https://doi.org/10.1068/a35111.

Vaccaro, Ismael, Oriol Beltran, and Pierre A. Paquet. 2013. "Political Ecology and Conservation Policies: Some Theoretical Genealogies.” Journal of Political Ecology 20:255-272.

Weng, Yen-Chu. 2011. “The Dynamics of Public Participation in Ecological Restoration: Professional Practitioners, Volunteers, and Institutional Differences.” Doctoral Thesis, United States -Wisconsin: The University of Wisconsin - Madison. https://search.proquest.com/docview/928458663/abstract/1455EF37EB344664PQ/1.

Willis, Daniel. n.d. "Harvard Design Magazine: Are Charrettes Old School?” Accessed June 4, 2018. http://www.harvarddesignmagazine.org/issues/33/are-charrettes-old-school. 


\section{Appendices}

Appendix A: Data Collection Instruments (Interviews and Focus groups)

1. Please introduce yourself.

2. What is your relationship to the Oak Savanna?

3. What role does the Oak Savanna serve in the larger community?

4. How do you use the Oak Savanna?

5. How often do you use the Oak Savanna and at which times do you use it most frequently?

6. What are your observations on the Oak Savanna's current use?

7. What is your favorite part of the Oak Savanna as it exists today?

8. What do you think could be changed about the Oak Savanna for the better?

9. What do you think motivated the re-design/expansion of the Oak Savanna?

10. Did you attend the Oak Savanna co-design meetings in 2017 ? Why or why not? (If so,) how did you hear about them?

If yes...

11. Describe for me what the co-design process was like. What were your observations on this process?

12. What was your input into the design process if any?

13. What kind of interests did you hear expressed from other parties?

14. Where there any barrier to you sharing your thoughts in the design process? If yes, what were they?

15. (Group/individual is shown prototype photos of co-designed OS) What is your favorite element of this design?

16. (Group/individual is shown prototype photos of co-designed OS) If you could change one element of this design, which would it be?

17. Do you feel personally that you were able to influence the design? Why or why not? Which elements of this design speak to your individual input?

18. How do you feel about the final design? Do you think it will help to restore the Oak Savanna? What about serving the community well?

\section{If no...}

10. If you had attended one of these meetings, how likely do you think you would have been to provide input? What input would you have provided in the co-design process had you'd attended? 
11. (Group/individual is shown prototype photos of co-designed OS) Here is an image generated by the design company who facilitated the co-design meetings of the re-designed Oak Savanna. Do you like it? Do you think this will help the Oak Savanna serve the community well?

12. What is your favorite element of this design?

13. If you could change one element of this design, which would it be?

14. Are there any other ways you would have personally influenced this design had you been given the chance?

\section{(Resume with question 19)}

19. I've brought with me today some arts \& crafts supplies. If you're willing, I'd like for you to create on a piece of paper your ideal Oak Savanna. Don't be limited to the constraints of the current area, try to image what the space would look like in your perfect world.

(After they are finished...)

Can you explain for me your creation and why you'd prefer the space to look like this?

20. Let's all compare our drawings to one another. What observations do you have about them side by side?

21. Let's compare these creations to the prototype for the co-designed space. What observations do you have about them side by side? 
Appendix B: Prototype Images

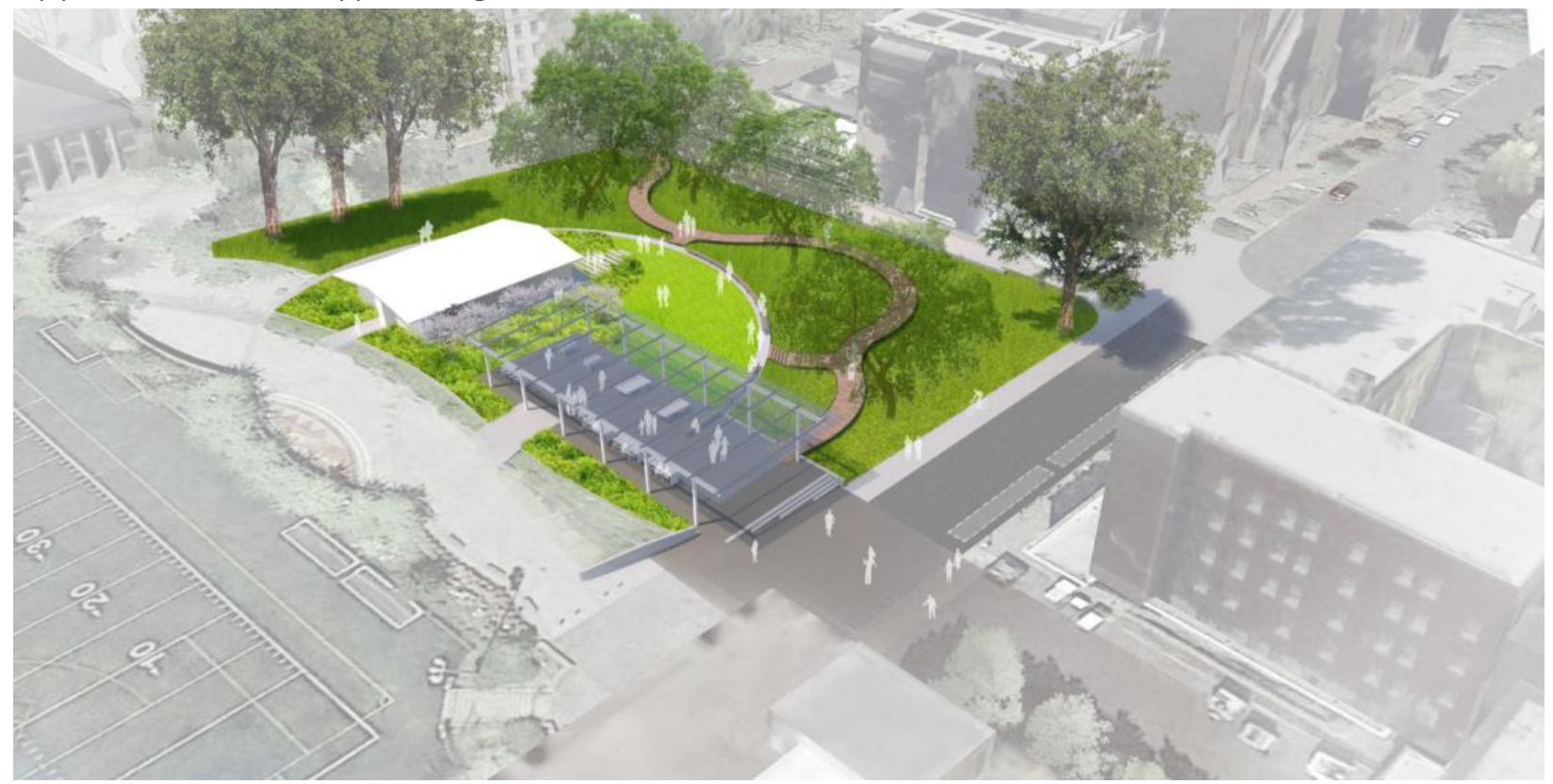

Figure 2 (above): The first of the five prototype images listed on the website of the design architects contracted by the planning team to facilitate the co-design meetings. This image is takes an aerial view of the Oak Savanna from above.

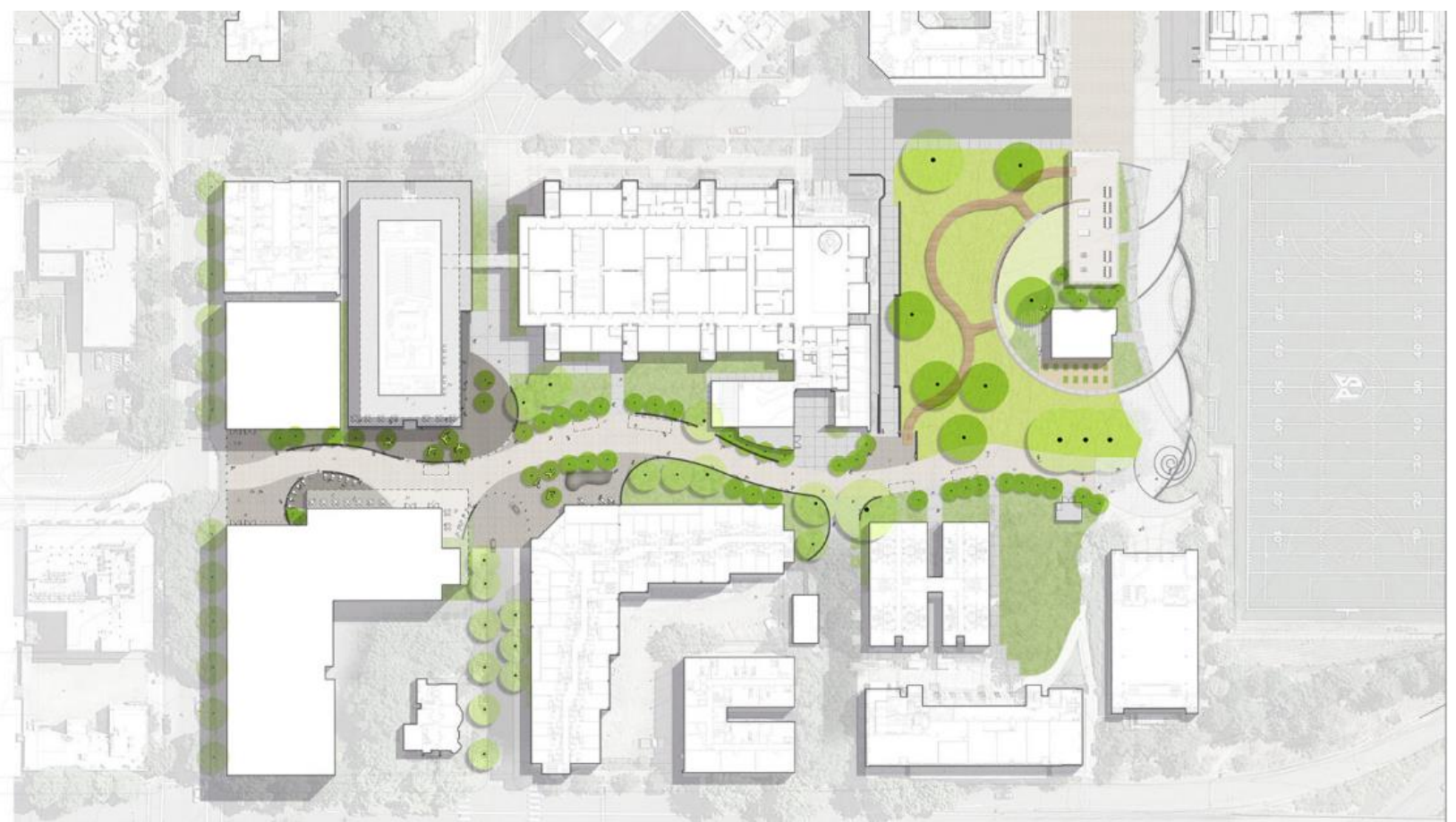

Figure 3 (above): The second of the five prototype images listed on the website of the design architects contracted by the planning team to facilitate the co-design meetings. This image is takes an aerial view of the neighborhood the Oak Savanna sits within from above. The Oak Savanna is differentiated from the surrounding buildings by depicting it in green. 


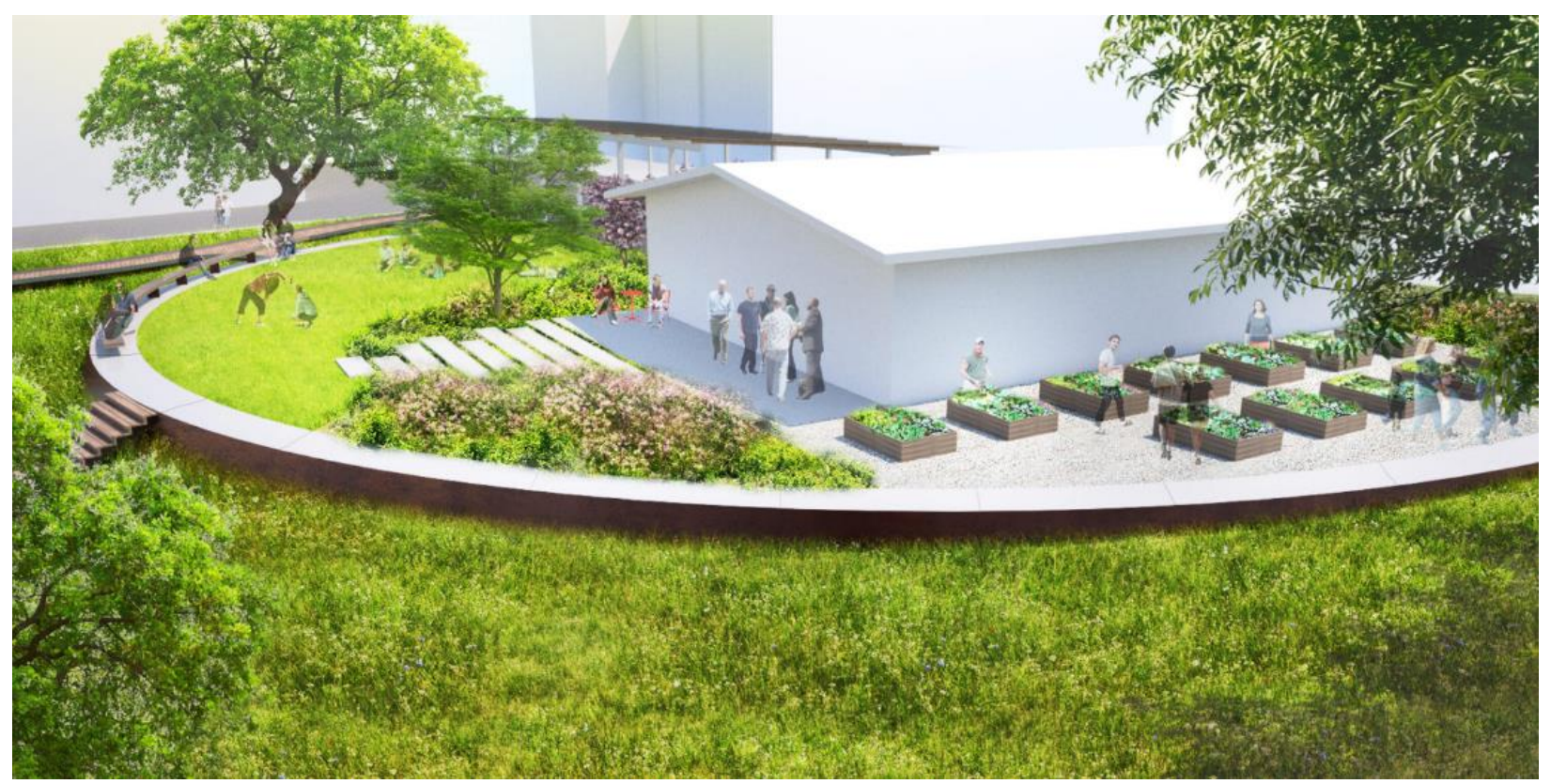

Figure 4 (above): The third of the five prototype images listed on the website of the design architects contracted by the planning team to facilitate the co-design meetings. This image is takes an on-the-ground view of the Oak Savanna from the north side. Individuals have been placed in the model to illustrate how it would be used.

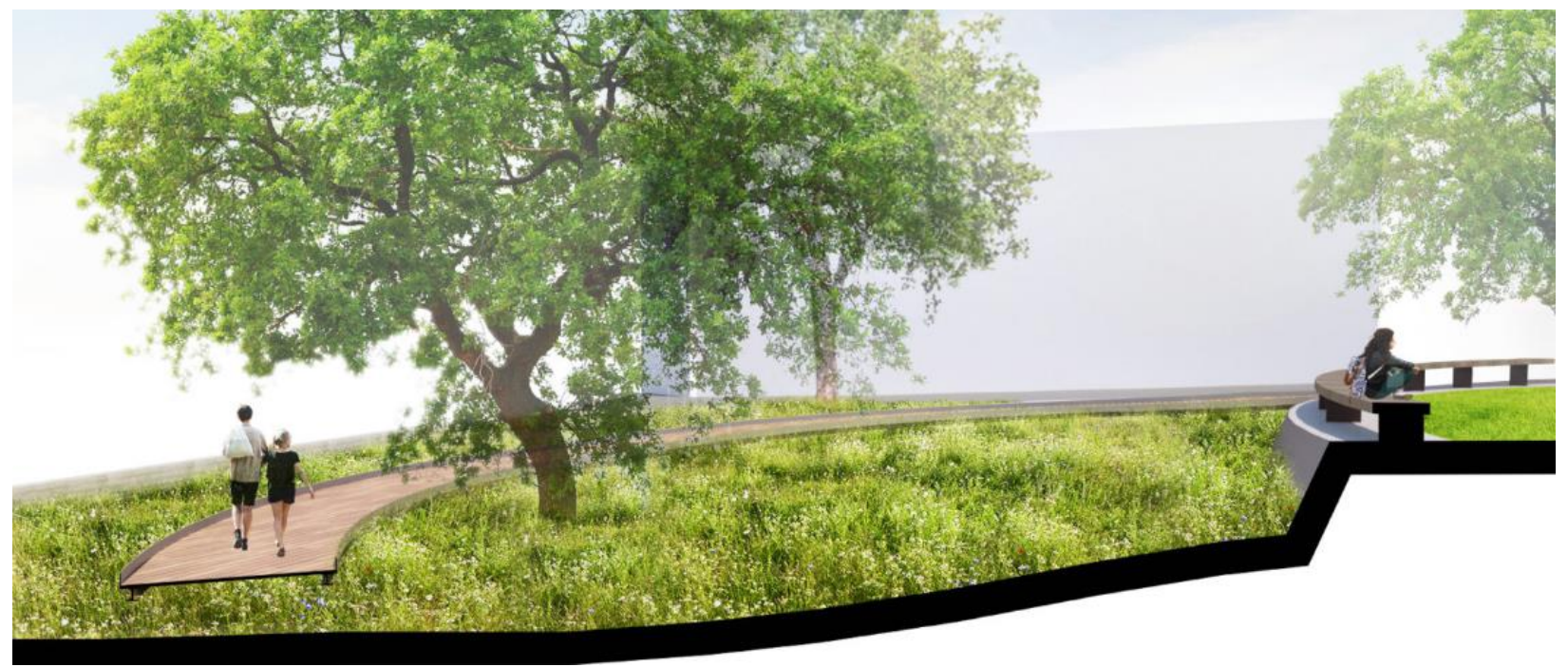

Figure 5 (above): The fourth of the five prototype images listed on the website of the design architects contracted by the planning team to facilitate the co-design meetings. This image is takes an on-the-ground view of the Oak Savanna from the southeast corner of the model. Individuals have been placed in the model to illustrate how it would be used. 


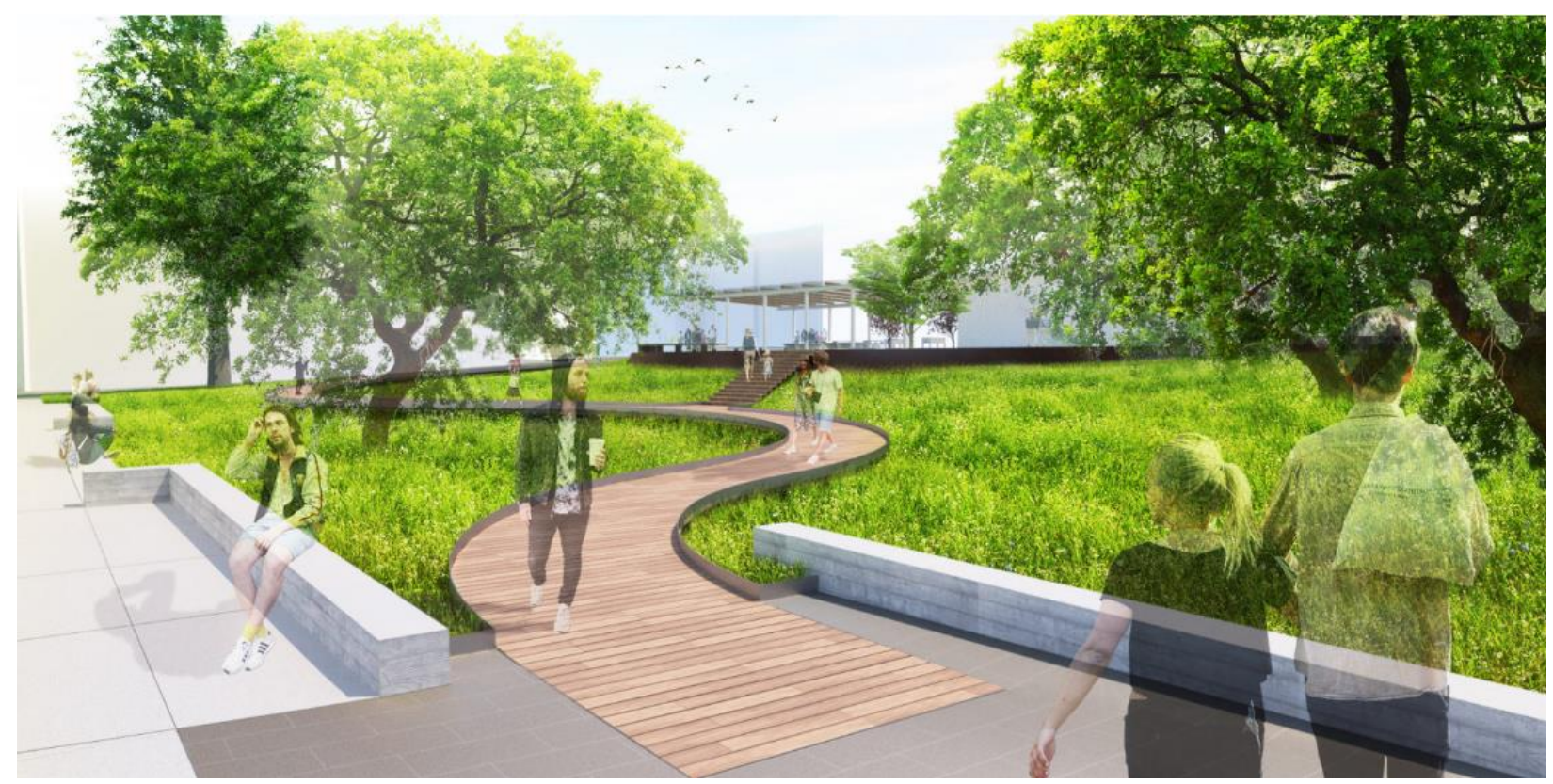

Figure 6 (above): The fifth and final model of the five prototype images listed on the website of the design architects contracted by the planning team to facilitate the co-design meetings. This image is takes an on-the-ground view of the Oak Savanna from the south side. Individuals have been placed in the model to illustrate how it would be used. 
Appendix C: Promotional Materials

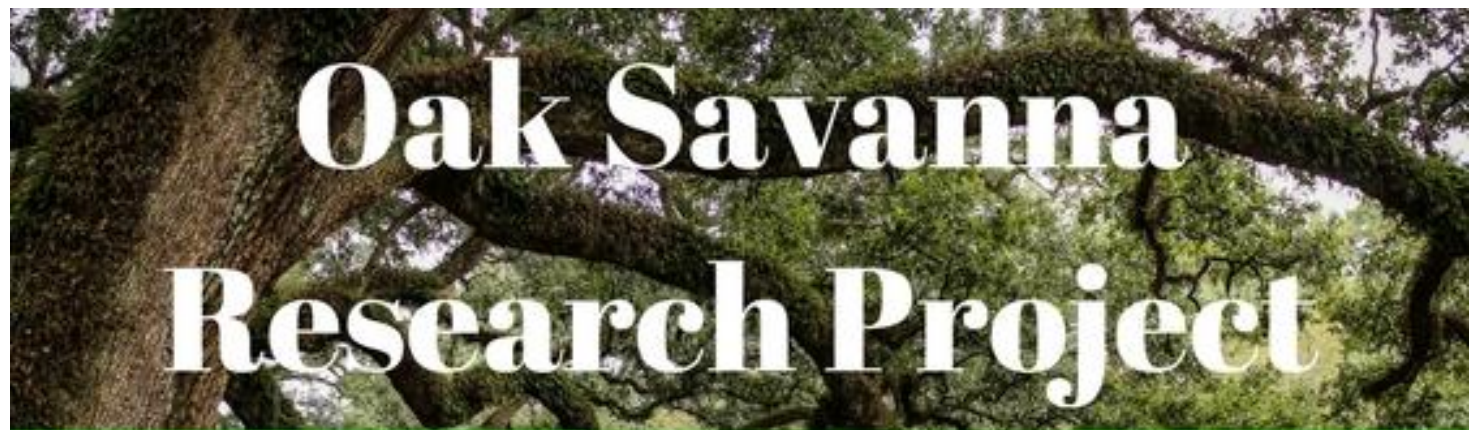

Do you regularly use the oak Savanna? Did you participate in the Oak

Savanna co-design meetings? Would you like to participate in research that

aims to understand how the co-design of the urban Oak Savanna at PSU

represents the interests of various stakeholder groups?

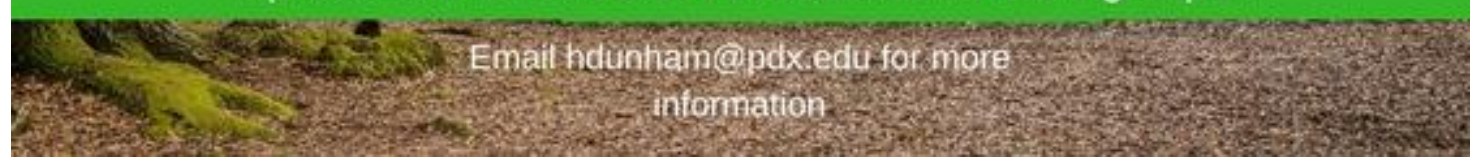

These materials were handed out to those who I interacted with during participant observation during which I briefly overviewed the interview process. 


\section{Appendix D: Informed Consent}

Hello. You are being asked to participate in a one on one interview that is being conducted by Haley Dunham, who is a fourth-year Anthropology student at Portland State University in Portland, Oregon. This research will study how the co-design of the urban Oak Savanna at PSU reflects various stakeholder's interests.

You are being asked to participate in this study because I believe you hold valuable and important knowledge about the area and its usage. By recording this information, I am better able to accurately understand the discussions that may unfold here today. The data recorded here today will be kept confidential until processed for the final document, which your name will not be included in.

Participating in this study should take no more than two hours of your time. This study aims to increase access to the renovated Oak Savanna by taking an inventory of different individual and group needs and assessing how well they are met by the new space that has been proposed so that all can benefit from this space, including dogs and wildlife. Questions for this interview will be broad and open ended, such as, "What is your relationship to the Oak Savanna?"

Although it is unlikely, this study may potentially result in changes to the Oak Savanna at Portland State University. It is my hope that these changes will benefit the land and all who visit it, but I am not in control of what happens to any green spaces at Portland State University. Risks associated with participating in this study include a breach of confidentiality and a significant use of time or inconvenience. To minimize these risk factors, the data will be stored in password protected documents on password protected electronic devices. The benefits of participating in this study include being offered a platform to voice feedback about the Oak Savanna project and contributing to the growing PSU community as a whole. If you have any questions or concerns I encourage you to communicate with me further as the coordinator of this research study.

Your name will not be used in any written reports and your participation in this study is completely voluntary. You have the right to choose to participate or to withdraw at any point in this study. This focus group or interview will be recorded and stored by the researcher for analysis. You can refuse to answer any question(s) that the researcher asks you or redact answers given from the focus group or interview at any time before the final report is published in midJune.

If you have any questions, concerns, or complaints at any time about this research study, I, Haley Dunham, would be happy to answer them at 661-335-1944 or hdunham@ @dx.edu. You may also contact the professor supervising this project at PSU, Jeremy Spoon, at jspoon@pdx.edu. If you would like to express an opinion about the study you're participating in to someone who is not the researcher or principle investigator, you may want to contact PSU's Office of Research Integrity athsrrc@pdx.edu.

Please sign below if this research study has been explained to you in full and all of your questions have been answered. By signing this document, you are agreeing that you understand the information described in this consent form and freely consents to participate. 
Name of Participant

$\underline{x}$

Date:

Signature of Participant

$\underline{\mathrm{X}}$

\section{For the Interviewee:}

Would you like a copy of the transcription from this interview/focus group: Yes No

Would you be willing to provide your contact information to be contacted for future research projects on the Oak Savanna or co-design of urban green spaces: $\quad$ Yes No

Contact: 